Alma Mater Studiorum - Università di Bologna DEPARTMENT OF ECONOMICS

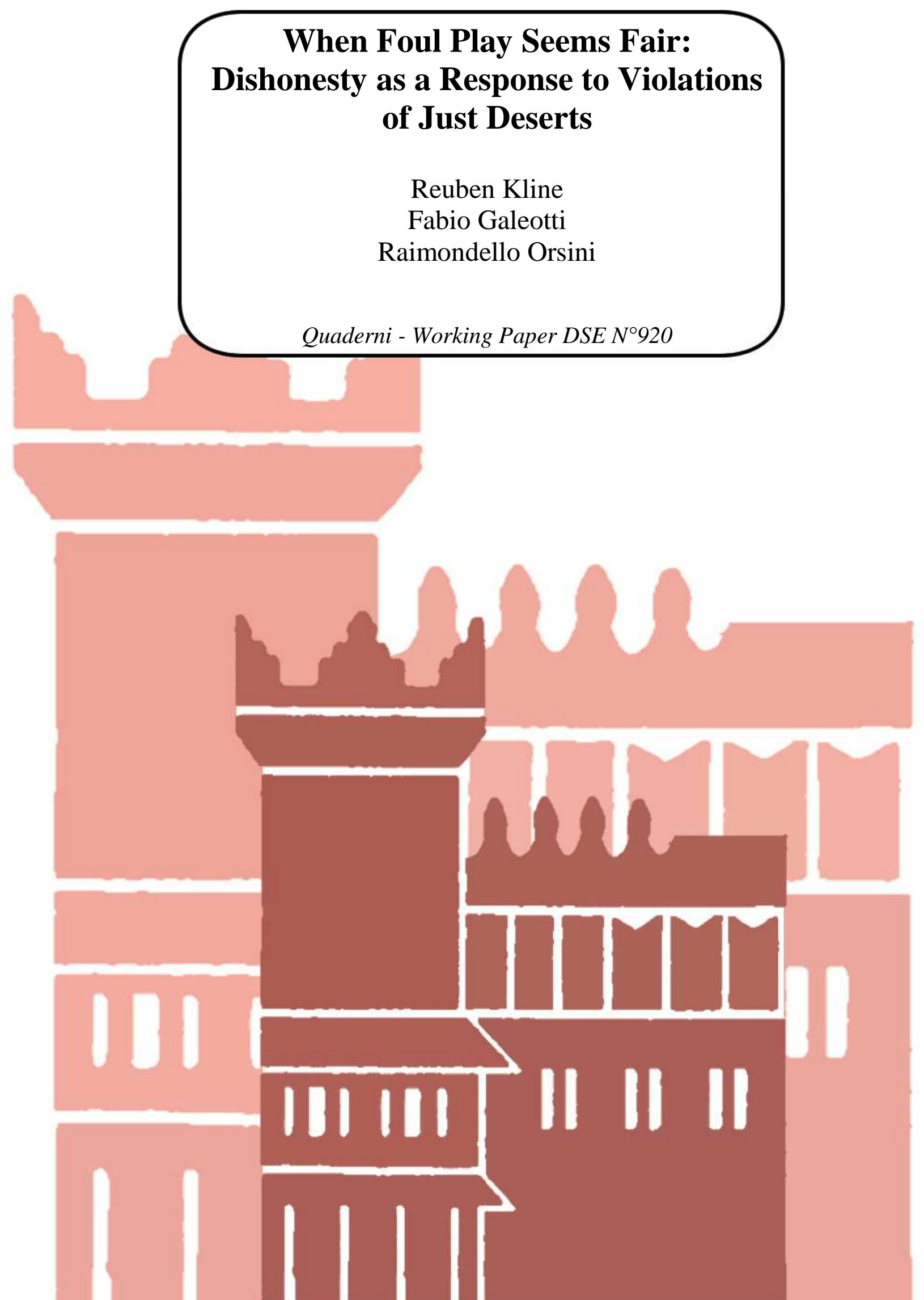




\title{
When Foul Play Seems Fair: Dishonesty as a Response to Violations of Just Deserts*
}

\author{
Reuben Kline ${ }^{\dagger}$
}

Fabio Galeotti ${ }^{\ddagger}$

Raimondello Orsini ${ }^{\S}$

January 21, 2014

${ }^{*}$ We wish to thank Maria Bigoni, Marco Casari, Peter DeScioli, Caterina Giannetti, Kevin McCabe, Itai Sened and seminar participants at George Mason, the Beelab 2013 Workshop (Florence), NorMAS International Workshop (Leiden), 2012 ESA International Meeting (New York), the 2012 Antigua Experimental Economics conference and the 2013 NYU-CESS Experimental Political Science Conference for useful feedback and advice. We thank the Russell Sage Foundation's Small Grants in Behavioral Economics (9811-05); MIUR - FIRB Project SONIC - A behavioral approach to social norms and intertemporal choices, (RBFR084L83001); and CFICEI for generous financial support. We thank Jen Sidorova for research assistance. The usual disclaimer applies.

†Stony Brook University. Corresponding author: reuben.kline@stonybrook.edu

${ }^{\ddagger}$ University of East Anglia, School of Economics and Centre for Behavioural and Experimental Social Science (CBESS), Norwich Research Park, Norwich, NR4 7TJ, UK; E-mail: f.galeotti@uea.ac.uk

$\S$ University of Bologna, Dipartimento di Scienze Economiche, Strada Maggiore 45, 40125 Bologna, Italy; E-mail: raimondello.orsini@unibo.it 


\begin{abstract}
We investigate the norm of just deserts and its effect on honesty. Just deserts is an essential norm in a market society, and honesty is an important factor in economic and social exchange. In particular, we analyze what happens when the social distributive rules betray the reasonable expectation that who deserves more will obtain a larger payoff. Using a formal-theoretic framework - equity theory - we explore the nexus between the perception of just deserts and honesty, combining cross-national survey (WVS) evidence and data from two laboratory experiments - conducted in the United States and Italy - to study whether violations of the principle of just deserts contribute to an increased tolerance for or an engagement in dishonest and corrupt acts. We find convergent evidence that violation of the just deserts norm results in a greater propensity toward self-serving dishonesty, and that this effect is distinct from the effect of inequality. Both the survey and experimental results also indicate that sensitivity to violations of the just deserts norm vary cross-nationally. We conclude with a discussion of the implications of our results for theories of distributive justice and multiple equilibria in societal levels of honesty.
\end{abstract}

JEL-Classification: C91, D03, D31, D63, H26

Keywords: Meritocracy, Equity, Honesty, Just Deserts, Cross-country Experiment, World Values Survey 
"If people feel that they are taken advantage of, why should they not rip off the system in return?"

— Elster, Solomonic Judgements

"Justice is a curious mixture of equality within inequality."

— Homans, Social behavior: Its

Elementary Forms

\section{Introduction: Honesty and Just Deserts}

Norms play a crucial role in the functioning of any socio-economic system. In particular the norms of trust and honesty are important norms for economic, political and legal development (Guiso et al., 2008; Uslaner, 2008; Rose-Ackerman, 2001a; Rothstein and Uslaner, 2005; Rose-Ackerman, 2001b; Zak and Knack, 2001) as they reduce the riskiness of market transactions in a world of uncertainty and incomplete contracts (Robert and Arnab, 2013). While trust and honesty help facilitate market exchange, a market economy paradigmatically relies on a meritocratic norm - henceforth meritocratic equity or just deserts - to give legitimacy to the inequality of the distribution of income in society. The presumption of this norm is that one deserves the income one has, as a function of merit ${ }^{1}$. While the belief in the extent to which just deserts should play a role in the distribution of income within a society varies across individuals in large part as a function of political ideology (Lewin-Epstein et al., 2003; d'Anjou et al., 1995; Mitchell et al., 2003), and context (Scott and Bornstein, 2009), most individuals in advanced industrial societies support the principle of merit as one (perhaps among several) criterion in decisions regarding distributive justice (Scott et al., 2001; Kunovich and Slomczynski, 2007). The fact that it is a norm suggests that it might also vary across cultures - indeed even among advanced industrialized market economies the

\footnotetext{
${ }^{1}$ As pointed out by Sen (2000), the principle of merit is instrumental and its definition contingent on our view of a good society (which in turn defines which activities are good and which actions are right). The practice of rewarding merit being underdefined, it needs to draw on other normative theories to get a precise content. We define merit as productivity (the result of skill plus effort), adopting the economic approach of rewarding merit on the basis of consequences: actions are to be rewarded for the good they do, so that incentives are well defined to produce a better and more efficient society in the long run.
} 
support for the principle of just deserts may vary substantially (Kunovich and Slomczynski, 2007; Osberg and Smeeding, 2006; Svallfors, 1997; Kelley and Evans, 1993; Gijsberts, 2002).

In this study, we investigate the relationship between these norms - honesty on the one hand, and just deserts on the other. Our principal hypothesis-based on equity theory (Adams, 1963, 1965) - is that violations of the norm of just deserts can have a deleterious effect on honesty, inducing those who feel that the system is inequitable, to "rip it off" in turn. To investigate whether (actual and perceived) violations of the principle of just deserts increase the propensity toward dishonesty, we use the following two-part empirical strategy. First, drawing on data from the World Values Survey, we investigate whether a belief that "success in life is generally the result of luck and connections" is significantly correlated with a willingness to justify a number of corrupt or dishonest acts. ${ }^{2}$ This approach lends external validity in the form of a multinational, representative survey and allows us to establish that such association exists as a general predisposition across a large number of populations. In this multilevel analysis we are able to control for potentially confounding variables related to inequality at both the country level (observed income distribution, measured by the Gini index) and individual level (preferences for egalitarianism), and we find that the effect of just deserts is significant and substantial, over and above the effect of equality-related variables.

However, due to the limitations of cross-national survey data, we can neither establish causality within this relationship nor test whether this predisposition can manifest itself as behavior when dishonesty is an option to reduce inequitable payoffs that involve real money. In order to do so, we introduce a controlled, earned-income laboratory experiment in both the United States and Italy. We conduct the experiment in these two different locations to also investigate whether different industrial societies - in our case, American and Italian subjects - react differently to the norms of just deserts and honesty. This might be indeed the case as Americans seem to believe more strongly in the principle of just deserts than Italian and have an income distribution which is more reflective of the just deserts principle (Kunovich and Slomczynski, 2007). The first stage of the experiment is a real-effort task, in which we manipulate the degrees of equity and inequality of the reward (the income assignment procedure). We then pair high performing subjects with low performing subjects, allowing the high-performers to record the outcomes of a series of private signals in which a misrepresentation of the signals can materially benefit the high-performer at the expense of the low-performer. High-performing but rule-disadvantaged subjects in the inequitable conditions are more likely to be dishonest in such a way that earns them income at the expense of their randomly matched low-performing partner. This experimental design brings

\footnotetext{
${ }^{2}$ We use a single act-income tax evasion - for the purposes of illustration, but the relationship holds across eight different items which ask about different types of dishonest and corrupt acts.
} 
together two growing trends in experimental economics: "dishonesty" experiments, the vast majority of which follow the paradigm laid out in Fischbacher and Föllmi-Heusi (2013), and real-effort experiments, in which income (or a privileged role) is "earned" by performance on a quiz or task embedded in the experiment (Hoffman et al., 1994; Ruffle, 1998; Rutström and Williams, 2000; Jakiela, 2011; Esarey et al., 2012; Balafoutas et al., 2013; Durante et al., 2013).

As a result of this two-pronged empirical strategy, we uncover convergent evidence that the violation of the principle of just deserts increases dishonesty and corruption. This empirical strategy gives us more confidence in the generalizability of our causal inferences by virtue of the external validity of the nationally representative survey complementing the internal validity of the lab experiment. As such, we can conclude that the justification of dishonesty as a result of perceived lack of just deserts is both a general predisposition and a behavioral tendency.

The rest of the paper is organized as follows. In section 2 we review the literature focusing in particular on the way merit has been operationalized in experimental studies. In section 3 we formalize the theoretic framework. In section 4, we present the cross-national survey evidence of the attitudinal link between perceptions of unjust deserts and toleration of dishonesty and corruption. In section 5, we operationalize this relationship in the incentivized lab experiment. Section 6 discusses the broader implications of our findings and concludes.

\section{Related Literature}

There is extensive evidence from experimental economics that individuals care not only about the nature of the final distribution of income but also about the procedures that brought it about (e.g. Frey et al., 2004; Jakiela, 2011; Hoffman et al., 1994; Almås et al., 2010; Dal Bó et al., 2010; Konow, 2000, 1996; Rabin, 1993; Bolton et al., 2005). There are numerous theoretical and empirical studies of meritocracy in the behavioral economic tradition, with a number of theoretical conceptions of merit-based equity having been put forth, often combined with experimental tests.

Konow $(1996,2000)$ develops the "accountability principle" in which individuals are to be held responsible for outcomes under their control but not for factors outside of their control. Ooghe et al. (2007) and Schokkaert and Devooght (2003) develop a largely similar concept they call "responsibility-sensitive egalitarianism". Cappelen et al. (2010, 2007) manipulate the sources of rewards (i.e., whether they are earned or a result of luck) to test meta-preferences for equity, such as strict egalitarianism, libertarianism and liberal egalitarianism, the latter of which is functionally equivalent to Konow's accountability principle. 
Though they find heterogeneous preferences among their experimental subjects, there is a preponderance of "liberal egalitarians." Almås et al. (2010), demonstrate, through the use of a modified dictator game, that acceptance of equitable inequality (i.e. inequality generated by differential returns to effort and achievement) tends to develop during early adolescence. This study is based on an experimental design in which subjects first engage in a production phase where they can spend their time either working at a task (counting the appearance of certain numbers on a screen) or engaging in unproductive activity such as watching cartoons. Taken together, these results demonstrate that just deserts is among the most important criteria for establishing the equitability of income distributions. Our study builds on these to investigate the link between (un)just deserts and dishonesty.

In the laboratory, meritocracy is typically operationalized by assigning initial endowments and/or experimental roles based on performance on a task or quiz embedded within the experiment. In these designs high performance is rewarded with either a larger endowment or a (presumably) more privileged experimental role (if the experiment calls for heterogeneous roles). This condition is then typically contrasted with a condition in which the endowments or roles are randomly assigned. Among the first to use quizzes and/or tasks - as opposed to chance - to assign roles and/or initial endowments in an experimental setting, Hoffman et al. (1994) find that assigning the role of proposer in the Ultimatum game based on high performance on a quiz, causes responders to accept more unequal income allocations. Burrows and Loomes (1994) find that whether group income was earned or randomly assigned affects behavior in bargaining over the final allocation of payments. Ruffle (1998) finds that in ultimatum and dictator games proposers reward the effort that recipients put forth in an experimental task.

Other studies focus on the role of earned and unearned income in redistribution experiments. Durante et al. (2013) find that there is a reduced demand for redistribution of unequal incomes if this inequality is generated by performance on a "knowledge quiz," and that men are more prone to respond to such considerations. Rutström and Williams (2000) however, find that if the choice regarding redistribution is given to the subjects after they have earned their money, then preferences for redistribution more or less conform to what would be expected of purely selfish utility maximizers, that is, those with higher incomes support less redistribution and those with lower incomes prefer more distribution, and these preferences do not significantly differ even if the income differentials are unearned. Balafoutas et al. (2013) investigate the effect of equity and inequality considerations on the voluntary contribution mechanism with a redistribution scheme (either exogenously given or voted into place by the subjects). Their mechanism for earning income is also a quiz, but, unlike Rutström and Williams (2000), they find that subjects are more keen on redistribu- 
tion when income differences are the result of luck. Großer and Reuben (2013) find that even when income is earned in a double auction and subjects can vote on the level of redistribution, they nonetheless favor significant redistribution. Esarey et al. (2012) find that political ideology is associated with a willingness to redistribute unearned income, but not earned income. Using modified dictator games with earned and unearned income, Jakiela (2011) finds that standard American experimental subjects are more likely to reward effort as opposed to luck, while Kenyan villagers do not display this tendency.

Drawing more heavily on the Rawlsian tradition, a number of Political Science studies (Michelbach et al., 2003; Scott et al., 2001; Frohlich and Oppenheimer, 1992, 1990) find that multiple motives, including merit and maximin preferences drive distributive preferences, these include both incentivized and unincentivized experiments. Also invoking Rawls, Krawczyk (2010) finds that there are lower levels of redistribution when income is earned in a task than when it is random, though he finds that inequality of opportunity (as measured by a-priori probabilities of winning) does not affect levels of redistribution.

Studies of "organizational justice" investigate the equity of selection, evaluation and compensation procedures within organizations (Gilliland, 1993; Greenberg, 1987). Especially interesting for our theme of inequity and its effect on dishonesty, Greenberg (1990) find that employee theft increases after unexpected pay cuts.

This large, interdisciplinary literature offers considerable evidence that just deserts is an important, though not exclusive, determinant of distributive preferences, and that it can be meaningfully operationalized and manipulated in the lab. An additional literature has developed around the use of survey data to study distributional preferences in a cross-national setting, and suggests that there are substantial within- and between-nation differences in the extent to which individuals perceive the income distribution in their society as being meritocratically fair (Fong, 2001; Alesina and Angeletos, 2005a,b; Alesina and La Ferrara, 2005). In this research, cross-national variation in these perceptions explains substantial variation in aggregate preferences for redistribution.

In addition to the research, both experimental and observational, that pertains to just deserts, there is a rapidly growing literature on the behavioral economics of cheating and dishonesty. Most germane to our own design is a literature that has grown out of a paradigm developed in Fischbacher and Föllmi-Heusi (2013). In this paradigm, subjects roll a die in private, the outcome of which determines their earnings (and/or the earnings of another subject) in one way or another. The subjects, however, are free to misreport the outcome of the die roll. Researchers are then able to determine whether certain outcomes of the die roll are observed with greater frequency than others. What is often observed is that while subjects, in the aggregate, do misrepresent the outcome, they do not do so in a way which 
maximizes their earnings. This paradigm has, in a short time, generated a large amount of literature (Erat and Gneezy, 2012; Bucciol and Piovesan, 2011; Shalvi et al., 2011; Suri et al., 2011; Shalvi et al., 2012; López-Pérez and Spiegelman, 2012, among many others). The work by Francesca Gino and others (Gino and Pierce, 2009, 2010; Ayal and Gino, 2011) is closer to ours in terms of its theoretical content as they all involve evaluations of equity theory. Where our design differs is in that its focus is on the manipulation of the income generating process as a function of performance on a real-effort task embedded in the experiment. Moreover, in these studies the effect of dishonesty on the part of the evaluator is such that the interests of the evaluator and the evaluated are aligned, whereas in our experiment, the effect of dishonesty is zero sum.

Finally, though it does not involve earned income manipulations, Houser et al. (2012) is also close to the spirit to our experimental design. They find that subjects who were given a small allocation in a dictator game (implemented with the strategy method) are more likely to (self-servingly) cheat when reporting the outcome of a subsequent coin flip, thereby increasing their total payoff. They posit that the increase in dishonest behavior is a result of a perceived violation of the egalitarian equity norm. We believe that dishonesty can result from perceived violations of other equity norms, in particular the norm of just deserts. However, because egalitarianism has also been shown to be an important criterion for evaluating distributive justice, we are careful to control for inequality in both the survey and experimental designs and analyses.

\section{Equity Theory}

"Equity theory" (Adams, 1965, 1963) motivates our hypotheses, our statistical modeling and our experimental design. According to equity theory, an individual evaluates the fairness of a given context by comparing the ratio of their own outcomes and inputs with the ratio of outcomes to inputs of another individual who serves as a reference point for interpersonal comparisons of equity. ${ }^{3}$ Unequal ratios cause the individual distress, which can be then be attenuated through a variety of mechanisms, including the modification of inputs and/or outputs (Gino and Pierce, 2009). In Adams' theory, inputs are broadly construed, and consist of "the participant's contributions to the exchange, which are seen as entitling him to rewards or costs", which in turn constitute the outcomes. Outcomes are typically (but

\footnotetext{
${ }^{3}$ Later reformulations of equity theory include, among others, an ordinal formulation (Moschetti, 1979). Adams' original formulation, however imperfect as a general theory (see Walster et al., 1973; Harris, 1976; Alessio, 1980; Huseman et al., 1987, for extensions and criticisms of the original theory), is more than adequate for our purposes.
} 
not necessarily) defined in monetary terms (as they are in this study). ${ }^{4}$

Gino and Pierce (2009, 2010) and Ayal and Gino (2011) investigate dishonesty as a mechanism for reducing the distress arising from inequity. However, due to the random assignment of roles and initial payments, the income assignment mechanism is not a function of merit. While these studies are closely related to ours, our work is, to the best of our knowledge, the first application of equity theory to the relationship between meritocratic equity (just deserts) and honesty. In our cross-national survey analysis, we investigate individual tolerance for the dishonest modification of outcomes as a function of individual's beliefs regarding just deserts. In our experiment, by directly manipulating meritocratic equity through the initial assignment of income based on relative performance on a real effort task, we test whether violations of meritocratic equity cause an increased behavioral propensity for the dishonest modification of outputs. To the extent that meritocratic equity is violated (or perceived to be violated), we hypothesize that we will observe a greater tolerance of or propensity toward the dishonest modification of outputs.

An equitable scenario (between persons A and B) is one in which the ratios of outcomes to inputs for both persons are equal. Formally, it is defined as:

$$
O_{A} / I_{A}=O_{B} / I_{B}
$$

where $O_{i}$ and $I_{i}$ are, respectively, the outcomes and inputs of individual $i=\{A, B\}$.

For example, imagine a scenario in which there are two hourly workers working on the same job in the same company. In the case where one worker works twice as many hours as the other, it is almost axiomatic that the former should be paid twice as much as the latter in order for the situation to be equitable, because these are the respective outcomes (wages) that, given the inputs (hours worked), would ensure equality between the two workers' ratios of outcomes to inputs. Conversely, inequity arises when these ratios are not equal, i.e. when $O_{A} / I_{A}>O_{B} / I_{B}$ or $O_{A} / I_{A}<O_{B} / I_{B}$. In our experiment, we manipulate the values of $O_{A}$ and $O_{B}$ across treatments by varying payments in the real effort task as a function of performance (which is dichotomized as "high"-above the median - and "low"-below the median).

For our purposes, assume that person B is the decision maker - that is, the individual who may take a dishonest action to reduce his distress caused by inequity. We can normalize his inputs such that $I_{B}=1$, and then solve for the value of $I_{A}$ that equalizes the two ratios.

\footnotetext{
${ }^{4}$ It has been pointed out that equity theory, with its focus on contributions (inputs) represents only one of several possible distributional rules (Leventhal, 1976). Indeed, inter alia equality and need are often invoked as distributional criteria. Nonetheless, these criteria are not mutually exclusive (Scott et al., 2001; Michelbach et al., 2003). We control for equality in our regressions and through our experimental design. Given that our experimental subjects (in both locations) consist of undergraduate students who are randomly allocated to different treatments, beliefs that need among the subjects is heterogeneous are likely to be minimal.
} 
We will denote the value of $I_{A}$ that equalizes the equity ratios as $I_{A}^{*}$. Because we normalize $I_{B}=1$, then $I_{A}^{*}=O_{A} / O_{B}$. When $I_{A}=I_{A}^{*}$, the scenario is equitable. Conversely, when $I_{A} \neq I_{A}^{*}$, the scenario is inequitable. There are different combinations of inputs and outputs that produce an equitable or inequitable scenario. These combinations are summarized in Table 1 where we also indicate whether the final distribution of the outputs is equal or unequal.

Table 1: Equitable and Inequitable scenarios

\begin{tabular}{ccccc}
\hline \hline Scenario & Inputs & Outputs & Inequity & Inequality \\
\hline 1 & $I_{B} \geq I_{A}$ & $O_{A}>O_{B}$ & Negative & Yes \\
2 & $I_{B}>I_{A}$ & $O_{A}=O_{B}$ & Negative & No \\
3 & $I_{B}>I_{A}$ & $O_{A}<O_{B}$ & Either & Yes \\
\hline 4 & $I_{B}=I_{A}$ & $O_{A}=O_{B}$ & None & No \\
\hline 5 & $I_{B}<I_{A}$ & $O_{A}>O_{B}$ & Either & Yes \\
6 & $I_{B}<I_{A}$ & $O_{A}=O_{B}$ & Positive & No \\
7 & $I_{B} \leq I_{A}$ & $O_{A}<O_{B}$ & Positive & Yes \\
\hline
\end{tabular}

Note: Negative inequity is disadvantageous for the decision maker (Person B), while positive inequity is advantageous. In Scenario 1 (as well as Scenario 7), we group together situations where $I_{B}$ is strictly greater (smaller) than $I_{A}$ with situations where $I_{B}$ is equal to $I_{A}$. This is because, within the equity theory framework, they are qualitatively identical (i.e. the predictions of the theory go in the same direction).

As Bloom (1999) points out, negative or disadvantageous inequity (which characterizes Scenarios 1, 2, and, potentially, 3) has a much stronger effect than positive or advantageous inequity on the behavior of the subject who has to evaluate the distribution and eventually take action. For this reason, in our experimental study, we focus on scenarios where the input of Person B (the decision maker) is greater than the input of Person A. More precisely, in our experiment, we only consider the first four Scenarios, with Scenario 4 as baseline. Hence we restrict here our analysis to Scenarios $1-4 .^{5}$ Since $I_{B}=1$ and $I_{A}^{*}=O_{A} / O_{B}$, a scenario is always inequitable when $I_{A} \leq 1<I_{A}^{*}$ (Scenario 1), $I_{A}<1=I_{A}^{*}$ (Scenario 2) or when $I_{A}>I_{A}^{*}>1$ (Scenario 3). A scenario is always equitable (Scenario 3 and 4 ) when $I_{A}=I_{A}^{*}=1$. Note that Scenario 3 can be equitable or inequitable depending on the value of $I_{A}$ relative to $I_{A}^{*}$.

In our experiment, the only information about inputs that is available to subjects is the performance ranking. ${ }^{6}$ Hence, the subjects know whether $I_{A}$ is larger, smaller or equal to

\footnotetext{
${ }^{5}$ The opposite situations, where the input of the evaluator and decision maker (Person B) is lower than the input of the other subject (Person A) might be worth of study too. The experimental analysis of these scenarios is left for future research.

${ }^{6}$ It is possible, of course, that subjects will have unobserved heterogeneity in beliefs regarding the ultimate
} 
$I_{B}$. We can then use $I_{A}^{*}$ as a measure of how much the performance of Person A would have to be differentially valued in order for the scenario to be equitable. The value of the $I_{A}^{*}$ parameter allows us to make predictions regarding the relative propensity toward dishonesty of Person B (who in our experiment is designated the "Custodian") in the various treatments. If $I_{A}^{*}>I_{A}$, the scenario's outcomes (i.e., payoffs) privilege A's inputs over B's inputs, whereas if $I_{A}^{*}<I_{A}$, the scenario's outcomes privilege B's inputs over those of A. Equity theory therefore predicts that selfish dishonesty (i.e. dishonesty which benefits B at the expense of A) may occur in the first case, whereas altruistic dishonesty (i.e. dishonesty on the part of $\mathrm{B}$ that benefits $\mathrm{A}$ at the expense of B) may occur in the second case. Below, we use the value of $I_{A}^{*}$ in each treatment to inform our hypotheses about the observed levels of dishonesty across treatments.

\section{A Cross-National Multilevel analysis of Just Deserts, Dishonesty and Corruption}

In this section, we investigate the effect of the just deserts of the income distribution on the propensity to tolerate or justify dishonest and corrupt acts. We conduct a multilevel (MLM) regression analysis of survey data consisting of more than 130,000 individual observations. Such a technique enables us to model cross-country variation of the explanatory variable resulting in a less noisy estimation of the relationship of interest. We employ a random-intercepts model to account for such variation. The use of MLM allows us to control for country-specific effects while simultaneously including country-level and individual-level attributes as independent variables. Such flexibility is important as the dataset we use for the individual level data - the World Values Survey (Inglehart, 1998) — consists of several hundred survey items administered in nearly 100 countries encompassing hundreds of thousands of respondents. A multilevel model can allow us to fully exploit all of this cross-national variation to obtain an efficient estimate of the association between variables at an individual level. MLM offers a middle ground between "complete pooling, in which differences between groups are ignored, and no pooling, in which data from difference sources are analyzed separately." (Gelman and Hill, 2007, p. 7). Such a middle ground produces more efficient parameter estimates than would a country random effects model.

We first test our hypothesis that tolerance of dishonesty and corruption is positively

source of any such performance differences. Nonetheless, such heterogeneity should not pose a problem for us given the randomization of our experimental design. Unlike in the real world, our design makes very transparent both the inputs and the outcomes of the scenario, therefore allowing for a clean test of the theory. 
associated with the perception of unjust deserts of the income distribution. In addition, we demonstrate that this association is robust to the inclusion of several important covariates, most importantly including measures of inequality aversion and country-level inequality.

\subsection{Data}

In the political economy literature there is a standard WVS item that is used to capture the notion of "just deserts" "hard work brings success" on a scale from 1-10, where 1 represents close agreement ("Hard work usually brings a better life."), and 10 represents strong disagreement ("Hard work doesn't generally bring success - it's more a matter of luck and connections."). Just deserts is our proxy for "perceived meritocracy" and as such it is the chief explanatory variable for all of our models. Our dependent variable asks respondents to rate, on a scale of 110 , whether "cheating on taxes if you have a chance" is "never justifiable" (1) or "always justifiable" (10). Our main behavioral hypothesis is that the coefficient on the just deserts variable should be positive and highly significant. In addition to this item, there are 8 additional items that relate to other dishonest or corrupt activities. These are all measured on the same scale of "justifiability", asking to what extent "claiming undeserved government benefits", "avoiding a fare on public transport", "joyriding", "lying", "paying cash to avoid taxes", "buying stolen goods", "keeping money you have found" and "failing to report damage you've done accidentally to a parked vehicle" are justifiable activities. The relationship between just deserts and the justification of the dishonest/corrupt act is remarkably robust across all of these various conceptualizations of dishonesty/corruption. Here we focus on the "taxes" item, but the overall effects are virtually identical irrespective of which of these dependent variables we use. Some of the results from these other models are available in the supplementary appendix.

We include three other relevant survey items (individual level variables) as controls: the first gives a self-reported measure of the respondent's household income, measured in ten steps with a higher step representing a higher income. Note that these are not income deciles, but rather ranges of (self-reported) income. Second is a measure of trust which takes values of 1 , corresponding to "Most people can be trusted" and 2, corresponding to "Can't be too careful." Finally we include a variable which measures respondents' views on income equality by asking on a range of 1 to 10, whether "income should be made more equal" (1) or "we need larger income differences as incentives" (10). There are any number of country level variables that one might think it is useful to include in a model, however, here we opt for a parsimonious statistical specification, which includes only three country level predictors. We

\footnotetext{
${ }^{7}$ See, inter alia, Fong (2001); Bénabou and Tirole (2006); Alesina and Giuliano (2009); Alesina et al. (2001); Alesina and Glaeser (2004); Alesina and Angeletos (2005b); Alesina and La Ferrara (2005).
} 
include GDP per capita in purchasing power parity terms, taken from World Bank's WDI database; a measure of the country's income inequality (Gini coefficient), a number from 0-100 with higher levels representing greater inequality; and a measure of corruption at the country level taken from Transparency International's Corruption Perceptions Index (CPI), taking values from 0-10, with higher values representing less pervasive corruption.

Using the combined five waves of the World Values survey, we have a dataset including 84 countries, and 131,691 individual observations with a minimum of 298 and a maximum of 4,907 per country.

\subsection{Multilevel regression analysis}

Our variable of interest-(un)just deserts, that is, the higher the value, the less meritocratically equitable the respondent views the income generating process - captures the belief that within ones system, even if one works hard and plays by the rules, one still cannot "get ahead." We expect that there should exist a positive relationship between a belief in (un)just deserts and our dependent variable.

In a multilevel model, there are two (or more) levels of analysis. Here, we distinguish between the individual (level 1) and the country in which the individual resides (level 2). Results from LR test for a model with the constant only and intra-correlation class suggest that there is a significant amount of cross-country variation to explain and justify the use of a multilevel model. ${ }^{8}$

We thus estimate the following random intercept model: ${ }^{9}$

$$
\begin{gathered}
\text { taxevasion }_{i j}=\gamma_{00}+\gamma_{10} * \text { hardwork }_{i j}+\gamma_{20} * \text { equality }_{i j}+\gamma_{30} * \text { trust }_{i j}+\gamma_{40} * \text { income }_{i j} \\
+\gamma_{01} * \text { gini }_{j}+\gamma_{02} * c p i_{j}+\gamma_{03} * g d p_{j}+e_{i j}+u_{0 j}
\end{gathered}
$$

where hardwork, equality, trust and income are level-1 variables, and Gini, CPI and GDP are level-2 variables.

\footnotetext{
${ }^{8}$ What we are interested in is whether there are cross-country differences in tolerance of tax evasion and the relative size of these differences compared to the difference across individuals. The likelihood ratio test provides us with an answer to the first question. That is, the likelihood ratio test holds as a null hypothesis that the random effects ANOVA provides a fit equal to that of an ordinary regression with a single constant (a grand mean). Given the test statistic, we reject this hypothesis and conclude that there are significant differences across countries. Second, by calculating an intra-class correlation, using the values of $\tau_{00}$ and $\sigma^{2}$ (the formula for ICC is $\hat{\rho}=\frac{\tau_{00}}{\tau_{00}+\sigma^{2}}$ ) we can say that $\hat{\rho}=0.101$, indicating that approximately $10 \%$ of the variation in attitudes toward tax evasion is explained by variation across countries, whereas the remaining $90 \%$ is explained by individual level variation.

${ }^{9}$ We also estimated a number of models allowing for a random slope parameter, i.e. estimating countrylevel coefficients on our just deserts variable. These models explain less variation than otherwise identical models containing only a random intercept parameter and so are not reported here.
} 
In this model, the country-level intercept is estimated by:

$$
\beta_{0 j}=\gamma_{00}+\gamma_{01} * g i n i_{j}+\gamma_{02} * c p i_{j}+\gamma_{03} * g d p_{j}+u_{0 j}
$$

Table 2: Justifying Dishonest/Corrupt Acts: Random Intercepts Model

\begin{tabular}{lccc}
\hline \hline Variable & Coefficient & S.E. & P-value \\
\hline Hardwork & 0.069 & 0.002 & 0.000 \\
Equality & 0.002 & 0.002 & 0.465 \\
Trust & 0.004 & 0.014 & 0.786 \\
Income & 0.034 & 0.003 & 0.000 \\
Gini & 0.008 & 0.002 & 0.000 \\
Corruption & -0.006 & 0.013 & 0.639 \\
GDP & -0.001 & 0.0003 & 0.000 \\
$\gamma_{00}$ & 1.884 & 0.137 & 0.00 \\
$\tau_{00}$ & 0.716 & 0.061 & \\
$\sigma^{2}$ & 2.193 & 0.004 & \\
$N(\#$ obs $)$ & 131,691 & & \\
$M$ (\# groups) & 70 & & \\
Log-Likelihood & -290433.8 & & 0.000 \\
LR test $\left(\chi_{2,1}^{2}\right)$ & 10560.1 & & \\
\hline
\end{tabular}

Importantly for our principal hypothesis, those who score higher on hardwork (indicating that they think luck and connections are more important in determining success) are significantly more likely to justify cheating on ones income taxes. This effect is not substantively trivial, as it indicates that for every point increase in hardwork, there is a 0.07 point increase (on a 10-point scale) in justification of tax evasion. Given that income is also measured on a 10-point scale, we can compare the magnitude of its coefficient with that of hardwork and see that the effect of hardwork is twice the size of the effect of income. Nor is the statistical significance purely the result of such a large dataset (and the small standard errors that accompany it), as it is the case that two other level-1 variables (trust and equality) fail to achieve statistical significance. Finally, we do see that there are small, but highly significant, effects for the level-2 variables Gini and GDP, with their coefficients indicating that respondents in poorer and more unequal countries are more likely to justify tax evasion.

Because we calculate a random intercepts model, we can extract the country-specific intercepts from our models estimations, which can give us an idea of the extent to which income tax evasion is believed to be justifiable in the U.S. and Italy, our two countries of interest. The estimated intercept, $\beta_{0 j}$, for Italy is 1.96 (s.e. $=0.09$ ) and for the U.S. is 1.66 $($ s.e. $=0.05)$, indicating that Italian respondents are more likely to find tax evasion more 
justifiable. On the other hand, if we look at the average levels of the hardwork variable, we find that Americans are more likely to perceive their country as exhibiting a meritocratic income distribution as the average response is 3.68 (s.e. $=2.34$ ) in the U.S. sample compared to 5.31 (s.e. $=2.58)$ in the Italian sample.

At the level of the model we find a significant reduction in deviance ${ }^{10}$ of model 2 compared to model 1. Based on the values of $\tau_{00}$ and $\sigma^{2}$ in model 2 , the ICC $=0.246$, indicating that nearly $25 \%$ of the variance in the outcome is now explained by cross-country differences.

Our multilevel analysis provides us with some robust results which can serve as a roadmap for our analysis of the experimental results in the next section. We can conclude that there is a strong, positive relationship between the perceived inequity of the income distribution and the willingness to tolerate tax evasion (and a number of other dishonest or corrupt acts). Though these results have a strong degree of external validity, they likely suffer from significant endogeneity problems that the methods we employ here are not equipped to address. For this reason, we conduct a controlled incentivized laboratory experiment in the United States and Italy. In the experiment, we manipulate the meritocratic equity and the equality of the income generating process to study its effects on subjects' dishonesty. With an incentivized experiment designed to investigate the relationship between just deserts and dishonesty, we can test whether the general predisposition we uncover in the MLM data can also manifest itself as a behavioral tendency. Moreover, because we conduct identical experimental treatments in Italy and the U.S. we can investigate whether there are differences in behavior between the Italian and American subject pools, as might be expected given that in the MLM we estimate that $25 \%$ of the variation in the willingness to justify tax evasion is due to cross-country variation.

\section{The Experiment}

\subsection{Overview}

The experimental sessions were conducted at the LES (Laboratorio di Economia Sociale) Laboratory of the University of Bologna (Forlì Campus) in June 2011 and February 2013, and at the Center for Behavioral Political Economy at Stony Brook University (SBU) in April and November 2012 and February 2013. All subjects were students recruited using the on-line recruitment system ORSEE (Greiner, 2004). 144 subjects participated in the sessions conducted in Forlì and 164 subjects participated in the sessions run in Stony Brook. In the experiment, earnings were calculated in wolfies. At the end of each session subjects

\footnotetext{
${ }^{10}$ Deviance is equal to $-2 \times \log$-likelihood.
} 
were paid in cash and in private at the subjects' stations. Average payments were $€ 11.34$ (about $\$ 15$ ) at Forlì and $\$ 16.82$ at SBU. Each session lasted around 40-60 minutes, including instructions and final payments. The experiment was computerized and programmed using the software z-Tree (Fischbacher, 2007). Computer desks were divided by partitions in order to avoid eye contact between subjects. Subjects received instructions both on their computer screen and on paper. In the instructions, we avoided any suggestive terminology. A copy of the instructions can be found in an appendix. The experiment was divided into two main stages: a first stage with a real-effort task to measure performance/effort and assign initial endowments and the groups between which the random pairings are made for the second stage; and a custodial stage where we measured the level of dishonesty of one subject who was asked to record the transfers of money from a second subject's "escrow" account to her own account. ${ }^{11}$

\subsection{The Real-Effort Task}

The real effort task consisted in counting the occurrences of the letters "e" and "c" for each line of a 15-line text in German. ${ }^{12}$ Before starting the task, subjects were informed that, after its completion, they will be divided into two equally sized groups based on their relative performance. ${ }^{13}$ In particular, subjects whose performance was above the median were going to be designated "high performers," whereas subjects whose performance was below the median were going to be designated "low performers." Subjects were also told that they will be assigned to one of four possible scenarios which were defined by how the high and low performers were going to be remunerated for the task. ${ }^{14}$ More specifically, the instructions informed the subjects that "in three of the four scenarios the payment to the high performers will be greater than or equal to the payment to the low performers. In one out of the four scenarios the payment to the high performers will be less than the payment

\footnotetext{
${ }^{11}$ After the two main stages, we conducted another real-effort task, analogous to the one in the first stage, in order to gauge individual motivation and learning during the experiment. Before paying the subjects, we also asked them to fill in a demographic and psychological questionnaire. This questionnaire was not administered in the first sessions run in Italy for which, therefore, we do not have the information about the demographics of the participants. The details of these demographics are in the supplementary appendix.

${ }^{12}$ The text was taken from the Critique of Pure Reason by Immanuel Kant. In particular, we extracted two parts from Kant's book. In each session, the computer randomly assigned one part to the first real-effort task, and the second part to the second real-effort task. Hence, the order of the two parts was randomized across sessions. The reason of this randomization is that we wanted to control for the possibility that one part was easier to solve than the other when we compared the performance between the first and second real-effort task.

${ }^{13}$ The performance of each subject was measured by taking the deviation in absolute value between the true number of c's and e's in each line of the text and the number recorded by the subject. The lower the score the higher the performance.

${ }^{14}$ Each scenario corresponds to a different treatment of the experiment.
} 
to the low performers." ${ }^{15}$ The amount of money earned in the first stage was communicated to each subject immediately before starting the second stage, and it constituted the initial endowment with which each subject entered the second stage.

\subsection{The Custodial Stage}

In the second stage, each subject was matched with another participant. One subject was assigned the role of participant A, while the other the role of participant B. Participant A was the Owner of an "escrow" account which was credited with $\$ 15(€ 10)$. Participant B did not receive any additional endowment and played the role of the Custodian of the partner's account. After the assignment of the custodial relationships, the decision-making element of stage 2 began. Each subject designated as Custodian received a series of 25 consecutive binary signals generated at random from a symmetric binomial distribution. ${ }^{16}$ Each signal was either red or green and known only privately by each Custodian. ${ }^{17}$ The color of each signal was meant to instruct the Custodian whether to transfer an amount of $\$ 0.60(0.40 €)$ to herself (in case of a green signal) or leave it in the Owner's account (in case of a red signal). Each Custodian was asked to record the color of each signal received. Subjects were instructed that it was only the recording of the signal that affected payoffs, not the signal itself. Since each signal was private information of the Custodian, the design allowed the Custodians to misrepresent the signal (if they wished) enabling them to increase or decrease their own payoff at the expense or benefit of their partner. ${ }^{18}$ To make sure that subjects

\footnotetext{
${ }^{15}$ This information has potential implications for the incentive compatibility of the task, but nonetheless, this is preferable to deception. Since better performance on the task could potentially result in a lower payoff, the effort decision is taken under uncertainty and, ex ante the task may not be fully incentive compatible. To measure the actual distance from full motivation, we had the subjects complete a similar, but fully incentivized effort task at the end of the second stage, and we solicited self-reported assessments of effort on a $0-4$ scale for each of the two tasks. Subjects performed significantly better (Wilcoxon signed-rank test, $p=0.000)$ and reported a significantly higher effort $(p=0.000)$ in the second (fully incentivized) task. However, the difference between the two self-reported efforts was tiny (the mean self-reported effort in the first real-effort task was 3.31, in the second 3.50). In addition, in both tasks, the majority of people (86\% in the first real-effort task, $92 \%$ in the second) reported an effort of 3 or 4 . We can thus attribute most of the better performance in the second real-effort task to learning rather than lack of incentives in the first task. Note also that if subjects did not take seriously the first real-effort task, our manipulation would have been less effective. This however is not the case as we observe strong behavioral differences across treatments in line with the prediction of equity theory. Hence, if anything, this potential confound works against our hypothesis, and thus the true effects may be even stronger.

${ }^{16}$ The signal generating process was carefully explained to the subjects. In particular, it was described as being equivalent to a coin flip.

${ }^{17}$ It was common knowledge that the revelation of the signal itself was private; that is, only the Custodian, but not the Owner of the escrow account knew the actual realization of the signal. The experimenters also knew with certainty the realization of each draw, but, of course, the subjects were anonymous to the experimenters, and thus the decisions of each subject could not be attributed to them personally.

${ }^{18}$ The amount of each possible single transfer was equal to $1 / 25$ of the total value of the escrow account $(\$ 15 / € 10)$ contained in the Owner's account. Hence, given the symmetry of the binomial distribution, the ex ante expected value of the final amount of money, which remained in the account after the task, was one
} 
understood the procedures, we asked them to complete some practice rounds with forced input before starting the task. In these rounds, subjects were encouraged to experiment with the recording of the signals and to observe the effect it had on payoffs - both theirs and their partner's. Thus, they were able to observe that a signal misrepresented as green rather than red would in fact result in an increase in their own payoffs. This measure was meant to ensure that the subjects realized they could misrepresent a red signal with impunity. ${ }^{19}$ Figure 1 shows the computer screen faced by a Custodian. During the task, while the Custodians reported the color of the signals, the Owners of the account were asked to predict the number of red signals that the Custodian would report. ${ }^{20}$

To characterize the qualitative nature of the Custodians' dishonesty, we borrow the typology developed in Erat and Gneezy (2012). Their typology of lying is based on its effects on the payoffs of the liar and another party. They differentiate between "altruistic" and "Pareto" white lies, in which the liar benefits another party, either at his own expense (altruistic) or in such a way as to be beneficial to both (Pareto). They define a black lie as one which is detrimental to the other party. There are "spiteful" - hurting both parties - and "selfish"- hurting only the other party - black lies. In our experiment, because the reporting of the signal has a zero-sum effect on payoffs, if the Custodian is dishonest, it is either a "selfish black lie" (selfish dishonesty) — when the Custodian reports a red signal as green — or an "altruistic white lie" (altruistic dishonesty) — when he reports a green signal as red. We are primarily interested in the selfish black lies, because it is this type of lie that we hypothesize should result from perceptions of negative inequity. However, we also investigate the role played by altruistic white lies, though we expect that those will be much less common than the selfish sort.

\subsection{Treatments}

In the experiment, we manipulate, along both the equity and equality dimensions, the remuneration of the first stage as a function of the relative performance of the participants in the real-effort task. In particular, we crossed, in a between-subject fashion, two dimensions of the income distribution: (meritocratic) equity and equality. This resulted in 4 treatments, as summarized in Table 3.

half of the initial endowment, allowing for an equal split of the endowment between the two partners. Note that this is the case if and only if the signals are reported honestly by the Custodian.

${ }^{19}$ It was crucial that the subjects realize that they could misrepresent the signal they receive. In this manner they are constrained only by their ethical scruples and not by a fear of shame or retribution for their actions.

${ }^{20}$ The prediction was not incentivized. 


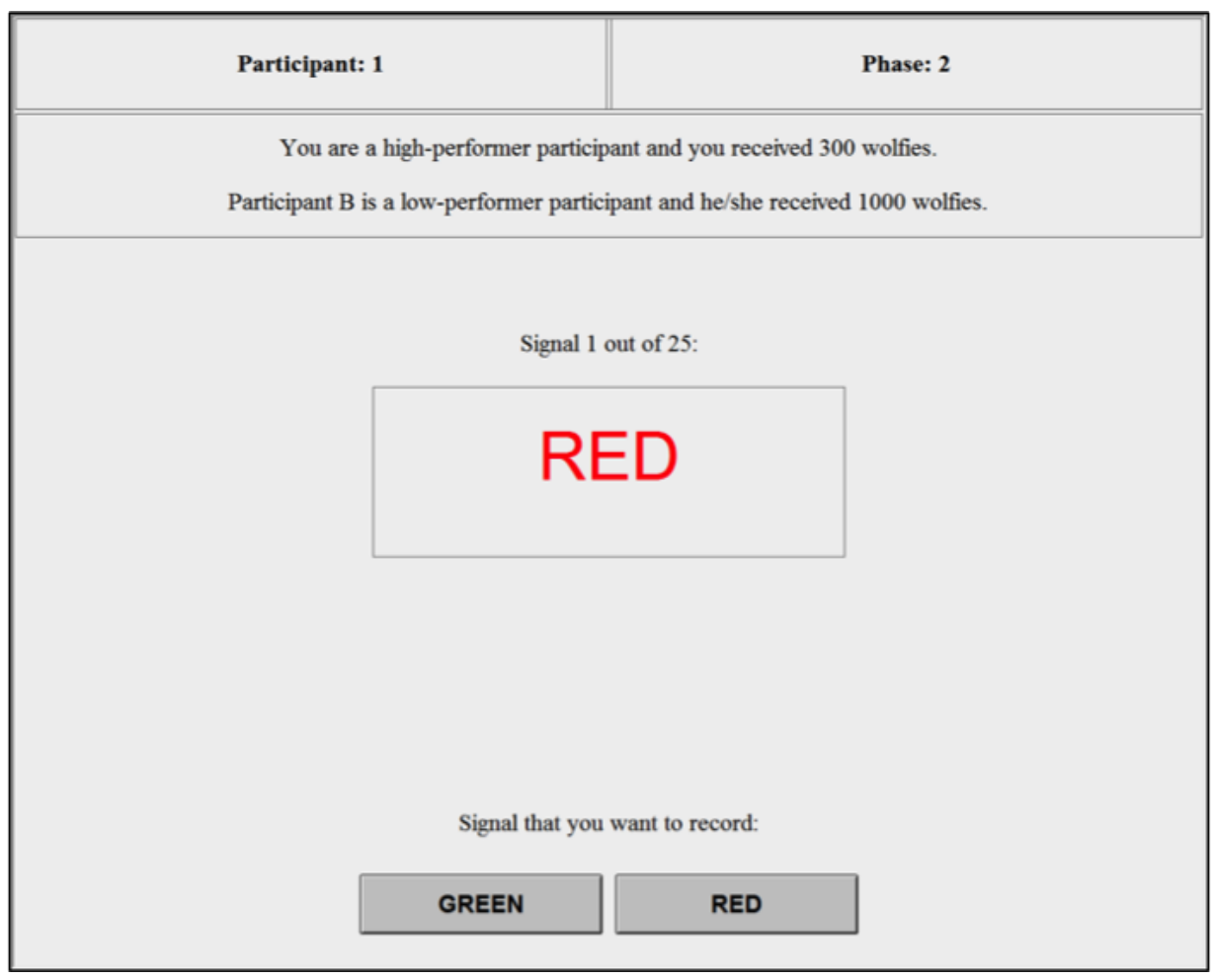

Figure 1: Screenshot of Signal Reporting Stage

Table 3: Two-factor design: Equality and Equity

\begin{tabular}{ccc}
\hline & \multicolumn{2}{c}{ Equity } \\
\hline \hline \multirow{2}{*}{ Equality } & Equal/Equitable & Equal/Inequitable \\
& Unequal/Equitable & Unequal/Inequitable \\
\hline
\end{tabular}

\subsubsection{Treatment EE: Equal and Equitable}

In this treatment, the distribution of the income is equal: both high and low performers receive the same remuneration after the first stage. Moreover, it is also equitable: subjects are (randomly) paired high with high performers and low with low performers in the second stage of the experiment. This means that in some cases (and unique to this treatment) the low-performers are in the decision making role (what we denoted as $B$ above), whereas in the others, the high performers are so positioned. Thus, the income distribution among partners is both equal and equitable because both subjects within each pair are compensated with the same amount for an identical category of performance. To control for income effects we conduct two sub-treatments, in which both high and low performers receive a remuneration of $\$ 10$ ( €7) in the high income sub-treatment and $\$ 3$ (€2) in the low income sub-treatment. In both of the income sub-treatments the payments are equal-so $O_{A}=O_{B}$, and because the 
pairings are homogenous with respect to performance, then the inputs must be equal, and so $I_{A}=I_{B}$. Therefore, $O_{A} / I_{A}=O_{B} / I_{B}$. This situation is equivalent to Scenario 4 in Section 3. Because in the EE treatment (and only in the EE) the pairings are homogeneous with respect to performance, the relative valuation attached to each type of performance is of no relevance for ones decision (assuming that the Custodian's psychological referent is indeed the subject with whom he was paired). Moreover, there is no information provided within the context of the experiment that would allow the subjects to differentially assign just deserts, as the members of each pair are objectively indistinguishable. Thus, this treatment allows us to determine a baseline level of (selfish and altruistic) dishonesty that should - by the design of the experiment-be divorced from concerns of equity.

\subsubsection{Treatment EI: Equal and Inequitable}

In this treatment, the distribution of the income is equal: both high and low performers receive the same remuneration after the first stage. However, it is inequitable: high performing subjects are (randomly) paired with low performers in the second stage of the experiment. This situation is equivalent to Scenario 2 in Section 3, where $O_{A}=O_{B}$ but $I_{B}>I_{A}$. Because the outcome (initial endowment) for each of the pair was equal $\left(O_{A}=O_{B}\right)$, the scenario would only be equitable if $I_{A}=I_{B}$. That would imply an identical valuation of both low and high performance, meaning that $I_{A, E I}^{*}=1$. This implies that if one has even the slimmest belief in just deserts (i.e., that higher performance deserves a higher reward) then this is an inequitable scenario for B (the high performer). High performers receive compensation equivalent to their low-performing partners, despite the common knowledge of their superior performance. Just as in the EE treatment, to control for income effects, we conduct two sub-treatments, where both high and low performers receive a remuneration of $\$ 10(€ 7)$ (the high income sub-treatment) and $\$ 3(€ 2)$ (the low income sub-treatment).

\subsubsection{Treatment UE: Unequal and Equitable}

In this treatment, the distribution of the income is unequal: the high performers receive a remuneration of $\$ 10(€ 7)$ after the first stage of the experiment, while low performers receive a remuneration of $\$ 3(€ 2)$. Subjects were (randomly) paired high-low performers. Hence, the income distribution between partners could be viewed as equitable, depending on the relative valuations placed on high and low performance. More precisely, $I_{A, U E}^{*}=3 / 10$ (or $2 / 7$ in the Italian sessions), or, in other words low performance- $I_{A}$ - must be discounted by a factor of $0.3(0.29)$ relative to high performance $-I_{B}$-in order for the scenario to be equitable. $^{21}$ This treatment can be described by Scenario 3 in Section 3.

\footnotetext{
${ }^{21}$ Thus, there is a sensible value of $I_{A}^{*}$ which would render the scenario equitable. For this reason, we categorize this treatment as "equitable." Moreover, from the standpoint of the high-performer, the scenario,
} 


\subsubsection{Treatment UI: Unequal and Inequitable}

Here, the high performers receive a compensation of $\$ 3(€ 2)$ after the first stage, while the low performers received a remuneration of $\$ 10(€ 7)$. Hence, the income distribution between partners was both unequal and inequitable, since those who performed better in the real effort task were paid less than their partners who performed worse. In this treatment, $I_{A, U I}^{*}=$ $10 / 3(7 / 2)$, meaning that one could hold anti-meritocratic views (indicating a preference for rewarding poor performance) and still feel that the scenario is inequitable toward the highperformer, because in order for the scenario to be equitable, one must value low performance by a ratio of 10 to 3 ( 7 to 2 ) compared to high performance. Thus, even if one valued low performance over high performance at a ratio of 2 to 1 , the scenario would still be inequitable toward the high performer, thus giving a greater justification for (selfish) dishonesty to reduce the inequity. This treatment corresponds to what we refer as Scenario 1 in Section 3.

From the values of $I_{A, k}^{*}$ we can predict the relative levels of selfish dishonesty $D(k)$ in treatment $k$, thus $D(U I)>D(E I)>D(U E) \geq D(E E) .{ }^{22}$

We can contrast this to the prediction of a theory of purely self-interested dishonesty motives. Such a theory would predict that dishonesty across the treatments should be equal across treatments, especially because the signals can be misrepresenting with impunity - the only thing that would perhaps constrain dishonest behavior is a norm against dishonesty. Thus, if we find no differences across the treatments, then a theory of self interested dishonesty would better explain the results. ${ }^{23}$ On the other hand, differences consistent with the predictions of equity theory laid out above would be strong evidence in favor of our hypothesis that dishonesty increases as a result of violations of the just deserts principle, and does so as a way of modifying ones outcomes such that the resulting distribution is more equitable.

As it is clear from the description of the different treatments, the between-subjects manipulation also determines the way subjects were paired in the Custodial Stage, and this pairing was based on the subjects' performance in the real-effort task of the first stage. In the EE treatment, low performers were randomly paired with low performers and high performers

if inequitable, is advantageously so. So, we also use such a designation for the sake of convenience, so as to avoid a need to differentiate between positive and negative inequity.

${ }^{22}$ The valuation of performance is not relevant for the decision in Treatment EE, because from the standpoint of the rules and information available B - a high (low) performer - cannot differentiate himself from $\mathrm{A}$-another high (low) performer. Therefore, so long as B uses A as a referent, $O_{A} / I_{A}=O_{B} / I_{B}$ and any selfish dishonesty in EE should not be a result of feelings of inequity. On the other hand, even if high performers were compensated for their performance in UE, the difference may be small enough that they believe the scenario still to be inequitable, and therefore equity theory does allow for some degree of selfish inequality in this case, depending on the beliefs of the Custodian as to how much high performance should be differentially rewarded. Thus we expect the same or a greater degree of selfish dishonesty in UE compared to EE.

${ }^{23}$ It would still, however, not explain why dishonesty wasn't maximal. 
with high performers. In the other three treatments, low performers played the role of Owners and were randomly paired with high performers, who played the role of Custodians. The role assignment is summarized in Table 4.

Table 4: Role-assignment in the four treatments

\begin{tabular}{lcc}
\hline Treatment & Owner & Custodian \\
\hline \hline EE & High (Low) performer & High (Low) performer \\
EI & Low Performer & High Performer \\
UE & Low Performer & High Performer \\
UI & Low Performer & High Performer \\
\hline
\end{tabular}

\subsection{Behavioral Hypotheses and Conjectures}

Our experimental design enables us to test two main behavioral conjectures. First, as in section 2 we uncovered a significant association between perceptions of unjust deserts and dishonesty, we seek some corroborating experimental evidence on that relationship. Our design allows us to measure the extent to which procedural unfairness induces dishonesty on the part of the Custodians. In particular, the following conjecture can be verified:

Hypothesis 1. Meritocratic inequity will induce greater selfish dishonesty on the part of those disadvantaged by the performance-payoff mapping, and to the extent that they are disadvantaged. More formally from the values of $I_{A, k}^{*}$ we can predict the relative levels of selfish dishonesty $D_{s}(k)$ in treatment $k$, thus $D_{s}(U I)>D_{s}(E I)>D_{s}(U E) \geq D_{s}(E E)$.

This hypothesis can be tested by measuring the extent to which the Custodians selfishly misrepresent the signal they receive. Across all four of our treatments, the Custodians are afforded the discretion of misrepresenting their private signals with impunity. Thus, the extent to which Custodians differ in their rates of selfish dishonesty across treatments represents an effect of manipulations. ${ }^{24}$

Hypothesis 2. Because the high-performer receives a higher initial payment in treatment $U E$, it is the only scenario in which positive inequity - inequity that benefits the Custodianmay arise. Therefore, we expect this treatment to have the highest amount of altruistic dishonesty. Any altruistic dishonesty in the other treatments must be motivated by something other than meritocratic equity concerns.

\footnotetext{
${ }^{24}$ Since there is no sanction for dishonest behavior, the theoretical prediction about the behavior of a purely self-interested Custodian is that he will report only green signals, irrespective of the actual signal received, which means a rate of selfish dishonesty of $100 \%$. The more a subject deviates from this prediction, the more he would appear to comply with the rules even though they are not enforceable. There were a handful of subjects, some in each of the treatments, who did, in fact, report 25 green signals, and thus would appear to be unaffected by the treatment. Removing these subjects from the analysis strengthens many of the results we discuss below.
} 
The next claim - in this case a conjecture rather than a hypothesis because it does not follow directly from our theory - that we consider concerns the differential reaction to unjust deserts in the U.S. and in Italy, and the overall attitude towards dishonesty of the two countries. In particular, Americans believe more strongly in the principle of just deserts than do Italians (or any other nation for that matter) (Kunovich and Slomczynski, 2007). Moreover, the American income distribution is in actuality more reflective of the the just deserts principle (Kunovich and Slomczynski, 2007), and therefore Americans should be affected more by violations of the just deserts principle. Based on this evidence, we make the following conjecture:

Conjecture 1. American subjects will be more sensitive to violations of the just deserts principle as well as generally less dishonest than Italian subjects. ${ }^{25}$

\subsection{Experimental Results}

We now turn to the analysis of the data. We first conduct the analysis for the (selfish) black lies (selfish dishonesty). We then conduct the same analysis for the (altruistic) white lies (altruistic dishonesty). We define the rate of selfish dishonesty as the number of red signals reported as green divided by the total number of red signals received. This variable provides a normalized measure of the rate of (selfish) black lies. Figure 2 displays the rates of selfish dishonesty for each experimental treatment, distinguishing between sessions run in Italy and US. ${ }^{26}$ At first glance, it seems that the inequitable treatments (EI and UI) were characterized by a much greater degree of black lies, especially in the sessions run in US. Indeed if we look at the mean rate of selfish dishonesty across treatments, these relative magnitude of these rates is exactly as predicted by equity theory: $D_{s}(U I)=0.36>$ $D_{s}(E I)=0.31>D_{s}(U E)=0.25>D_{s}(E E)=0.19$ In addition, Italian subjects seemed to be generally more dishonest than American subjects. We can investigate more formally with non-parametric tests whether there is any difference in the rates of selfish dishonesty across treatments (to test hypothesis 1) and subject pools (to test conjecture 1). If we compare the rate of selfish dishonesty across treatments, in the aggregate, subjects displayed statistically significant higher rates of selfish dishonesty in the UI treatment compared to the UE and EE treatment respectively $(p=0.076$ and 0.004$)$, and in the EI treatment compared to EE treatment $(p=0.035)$. Though not all of the hypothesized treatment effects are as predicted

\footnotetext{
${ }^{25}$ Our conjecture is based in part on the finding that Americans perceive their economic system to be characterized to a greater degree by just deserts than do Italians (Kunovich and Slomczynski, 2007).

${ }^{26}$ Since we did not detect any statistically significant difference, both in aggregate and within each sample pool, between the high and low income sub-treatments of the EE and EI treatment respectively $(p>0.1)$, we pooled the data of the sub-treatments together. Similarly, we did not find any statistically significant difference, both in aggregate and within each sample pool, between the rates of selfish dishonesty of high and low performers in the EE treatment $(p>0.1)$, and, therefore, we pooled the data together.
} 
by equity theory, many are and the absolute magnitude of the degree of selfish dishonesty across treatments, is exactly as predicted by equity theory. To evaluate conjecture 1, we pool the data of the treatments together and compare the rate of selfish dishonesty of Italian and American subjects. We do not detect any statistically significant difference (Mann-Whitney test, $p>0.1$ ). Similarly, we do not detect any statistically significant difference between Italian and American subjects in we consider each treatment separately $(p>0.1)$. Based on these findings, we present our first result ${ }^{27}$ :

Result 1. In the aggregate, there is more selfish dishonesty in the inequitable treatments than in their corresponding equitable treatments. This is strong evidence of our hypothesis that the lack of just deserts causes an increase in selfish dishonesty. This finding, which is consistent with Hypothesis 1 represents a behavioral corroboration of the dispositional tendency we uncover in the MLM results reported in the previous section, thus providing convergent evidence of our principal empirical hypothesis. The predictions of equity theory were largely borne out, especially as regards the ordering of the treatments with respect to their levels of selfish dishonesty.

This result, however, appears to be mostly driven by the American subjects who display statistically significant higher rates of selfish dishonesty in the UI treatment compared to the UE and EE treatment respectively $(p=0.061$ and 0.019), and in the EI treatment compared to EE treatment $(p=0.011)$. American subjects also exhibited a much greater degree of black lies in the EI treatment compared to the UE treatment $(p=0.067)$. Italian subjects displayed significantly higher rates of selfish dishonesty in the UI treatment only in comparison to the EE treatment $(p=0.062)$. We can thus present our second result:

Result 2. American subjects are more sensitive to unjust deserts than Italian subjects as they tend to display lower rates of selfish dishonesty when the income distribution is equitable and higher rates when the income distribution is inequitable.

We now turn to the analysis of the (altruistic) white lies. We define the rate of altruistic dishonesty as the number of green signals reported as red divided by the total number of green signals received. This variable provides a normalized measure of the rate of white lies. Figure 3 displays the average rates of altruistic dishonesty for each experimental treatment,

\footnotetext{
${ }^{27}$ This result, as well as the following findings, cannot be explained by differences in the number of red signals - randomly generated by the computer for each Custodian - received by different Custodians across treatments, countries and subject types (high and low performers). We did not in fact detect any statistically significant difference across treatments, countries and subject types on the number of red signals received by the Custodians (Mann-Whitney test, $\mathrm{p}>0.1$ ).
} 


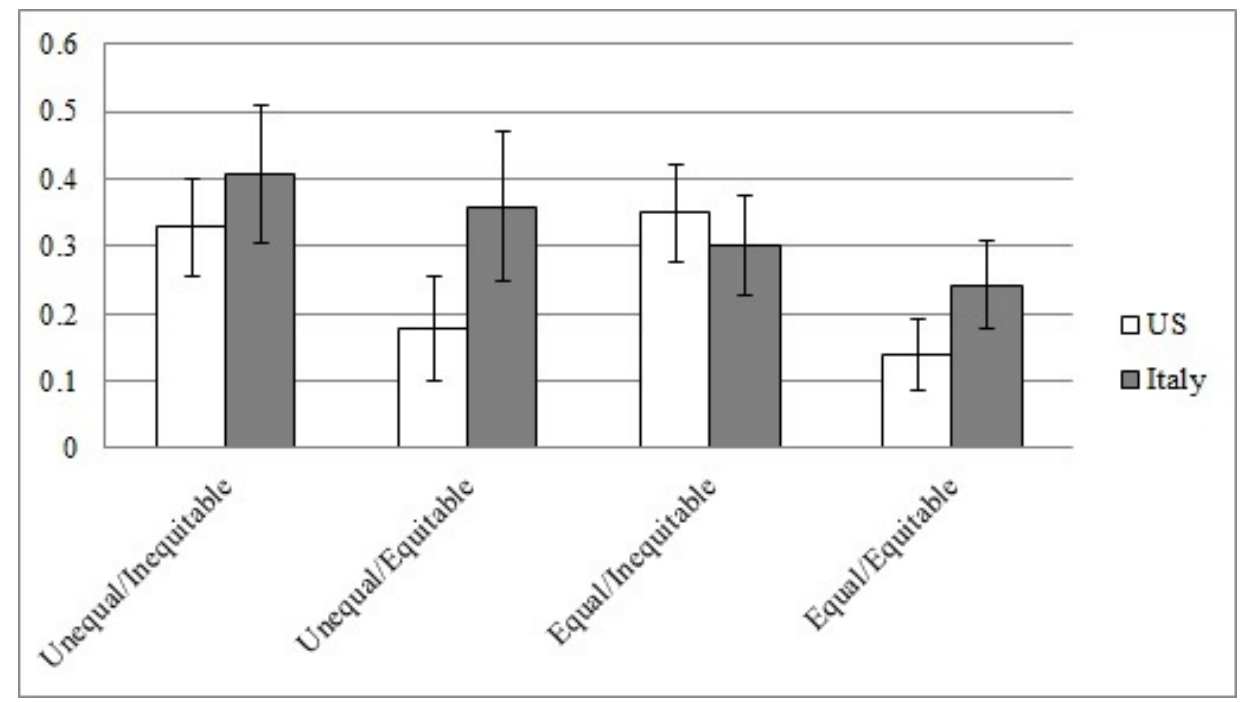

Figure 2: Selfish Dishonesty by Treatment

distinguishing between sessions run in Italy and the U.S. ${ }^{28}$ Overall, altruistic dishonesty was significantly higher in US compared to Italy (Mann-Whitney test, $p=0.027$ ), especially in the EE treatment $(p=0.088)$ and in the high income EI sub-treatment $(p=0.012)$. If we pool together American and Italian subjects we find no differences in the rates of altruistic dishonesty across treatments $(p>0.1)$. If we consider only the Italian sample, altruistic dishonesty was lower in the high-income EI treatment compared to the low-income EI, UI and UE treatment respectively ( $p=0.033,0.071$ and 0.033 ), suggesting that Italian subjects were sensitive to income effects when the income distribution was negatively inequitable toward the high performer. If we consider only the US sample, there was no difference in the rate of altruistic dishonesty across treatments $(p>0.1)$. The rates of altruistic dishonesty are much lower and much more noisy than the rates of selfish dishonesty, and they do not fit the predictions of equity theory particularly well. We suspect that this is because being disadvantaged by inequitable rules provides a greater justification for dishonesty than being advantaged by inequitable rules. Nonetheless, we can derive the following results:

Result 3. Treatment UE is not characterized by a greater rate of altruistic dishonesty than any of the other treatments. Thus, there is no systematic relationship between equity theory

\footnotetext{
${ }^{28} \mathrm{As}$ for the analysis of the black lies, we checked whether there was any statistically significant difference, both in aggregate and within each sample pool, between the high and low income sub-treatments of the $\mathrm{EE}$ and EI treatment respectively. We detected a statistically significant difference in altruistic dishonesty between the high and low income EI sub-treatments only in the Italian sample $(p=0.033)$. Hence, in the analysis of the data, we will analyze each sub-treatment of the EI treatment separately. We also checked whether there was any statistically significant difference, both in aggregate and within each sample pool, between the rates of altruistic dishonesty of high and low performers in the EE treatment. We did not find any difference $(p>0.1)$, and, therefore, we pooled the data together.
} 
and the the rates of altruistic dishonesty across treatments and therefore Hypothesis 2 is not supported by the evidence.

Result 4. Italian subjects displayed lower rates of altruistic dishonesty than American subjects, especially in the Equal treatments.

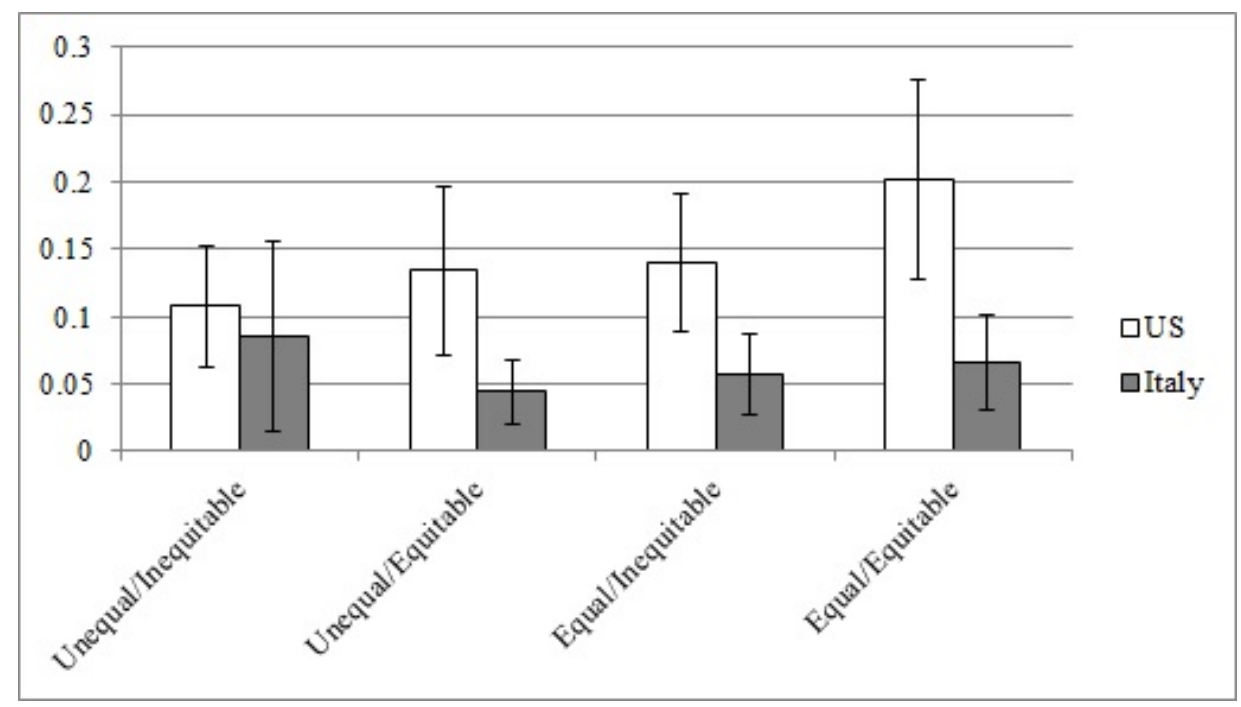

Figure 3: Altruistic Dishonesty by Treatment

Our measure of dishonesty (both selfish and altruistic), analyzed so far, is appropriate if we think of the decision to be dishonest as playing out independently for each signal received by the Custodian. It is likely, however, that subjects had a supergame strategy designed to realize a final distribution acceptable to the subject. To analyze such a strategy, we instead measure dishonesty as a ratio of the total number of red signals reported to the total number of red signals received (rate of overall honesty). This measure actually takes into account both types of dishonesty, selfish and altruistic, and thus could be greater than one if a subject engaged in altruistic white lies (i.e. reported the signal as red when it was in fact green).

Figure 4 displays the average rate of overall honesty for each experimental treatment. ${ }^{29}$ Overall, subjects in the U.S. were statistically significantly more honest than subjects in Italy (Mann-Whitney test, $p=0.026)$, especially in the UE treatment $(p=0.076)$ and EE treatment $(p=0.056)$. If we conduct pairwise comparisons of the treatments, pooling the data of the Italian and American sessions together, honesty was statistically significantly

\footnotetext{
${ }^{29}$ No statistically significant difference was found within the EE and EI treatments respectively between the low and high income subtreatments, both in aggregate and for each subject pool (Mann-Whitney test, $p>0.1$ ). Hence, we pooled the data of the subtreatments together. Similarly, we detected no difference, neither in aggregate nor within each sample pool, between the rates of overall dishonesty of high and low performers in the EE treatment $(p>0.1)$. Hence, we pooled the data together.
} 
lower in the UI treatment compared to the UE and EE treatment respectively $(p=0.075$ and 0.002), and in the EI treatment compared to the EE treatment $(p=0.064)$. If we consider only the Italian subject pool, honesty was statistically significantly lower in the UI treatment compared to the EI and EE treatment respectively ( $p=0.068$ and 0.031 ). If we consider only the American subject pool, dishonesty was statistically significantly lower in the UI treatment compared to the UE and EE treatment respectively $(p=0.072$ and 0.011$)$, and in the EI treatment compared to the EE treatment $(p=0.023)$. Altogether these tests bring us to the following two results.

Result 5. American subjects reacted more to just deserts than Italian subjects by reporting a larger proportion of red signals when the income distribution was equitable and a smaller proportion when the income distribution was inequitable.

Result 6. Italian subjects reported a smaller proportion of red signals than American subjects.

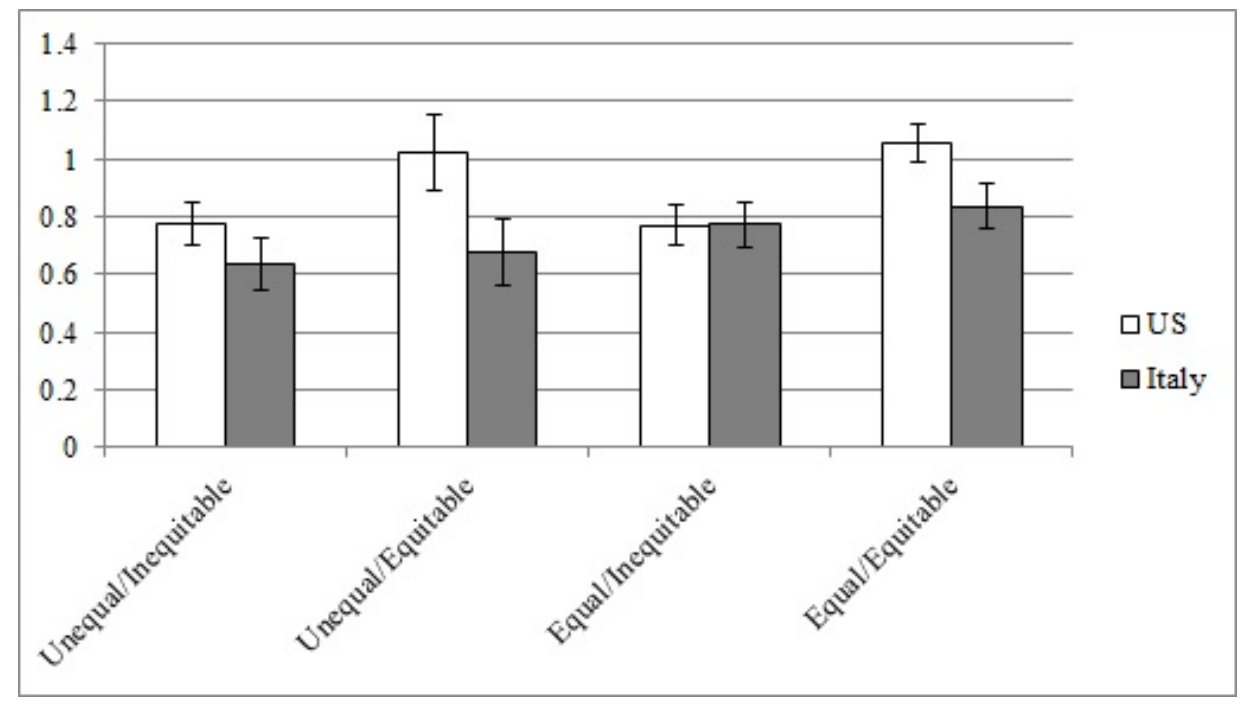

Figure 4: Rate of Honesty by Treatment

To test the robustness of the aforementioned results we conduct a regression analysis in which we are also able to investigate and control for the dynamics of dishonesty over the 25 signal periods. In particular, we run two separate regressions, one for the Italian sample and one for the American sample. We employ logit regressions with random effects to control for the non-independence of the observations at the subject level. The dependent variable is a dichotomous variable which takes value 1 if a signal is recorded as red and 0 if it is recorded as green. The independent variables are the actual signal ( 1 if red, 0 if green), the 
Table 5: Random Effects Logit regressions

\begin{tabular}{lcccccc}
\hline & \multicolumn{3}{c}{ US } & \multicolumn{3}{c}{ Italy } \\
\hline \hline & $\mathrm{b}$ & $\mathrm{se}$ & $\mathrm{p}$ & $\mathrm{b}$ & $\mathrm{se}$ & $\mathrm{p}$ \\
\hline Red signal $(\mathrm{t})$ & $4.321^{* * *}$ & 0.325 & 0.000 & $5.112^{* * *}$ & 0.406 & 0.000 \\
Red Signal $(\mathrm{t}-1)$ & $-0.416^{* *}$ & 0.173 & 0.016 & -0.271 & 0.196 & 0.167 \\
Red Signal $(\mathrm{t}-1)+(\mathrm{t}-2)$ & 0.142 & 0.201 & 0.481 & -0.009 & 0.235 & 0.971 \\
Red Signal $\times \mathrm{UI}$ & $-1.082^{* *}$ & 0.449 & 0.016 & $-1.575^{* * *}$ & 0.606 & 0.009 \\
Red Signal $\times \mathrm{UE}$ & $1.417^{* *}$ & 0.641 & 0.027 & -0.415 & 0.689 & 0.547 \\
Red Signal $\times \mathrm{EI}$ & $-1.188^{* * *}$ & 0.417 & 0.004 & -0.615 & 0.523 & 0.239 \\
UI & -0.846 & 0.682 & 0.215 & 0.291 & 0.797 & 0.715 \\
UE & $-1.287^{*}$ & 0.687 & 0.061 & -0.398 & 0.838 & 0.635 \\
EI & -0.741 & 0.594 & 0.213 & 0.164 & 0.645 & 0.800 \\
Effort & -0.207 & 0.261 & 0.428 & -0.106 & 0.325 & 0.743 \\
Period & -0.009 & 0.01 & 0.396 & -0.006 & 0.012 & 0.635 \\
Constant & -0.753 & 1.044 & 0.471 & $-3.059^{* *}$ & 1.204 & 0.011 \\
\hline Obs & 1886 & & & 1656 & & \\
Pseudo $\chi^{2}$ & 0.476 & & & 0.425 & & \\
Df & 11 & & & 11 & & \\
Prob $>\mathrm{F}$ & 0 & & & 0 & &
\end{tabular}

previous actual signal ( 1 if red, 0 if green), a dummy which takes value equal to 1 if the two previous consecutive signals were red, the treatment dummies (the baseline category is the EE treatment), interaction terms between the treatment dummies and the actual signal, the signal period ( 1 to 25 ), and the effort reported by the subject in the first real-effort task. ${ }^{30}$ The results of these regressions are reported in Table 5 .

Both American and Italian subjects were more likely to record a red signal when they received a private red signal. In addition, there is evidence that American subjects were less likely to report a red signal if the color of the previous signal was red. Once we controlled for these dynamics, we observe that American subjects in the UI treatment were less likely to send a red signal when they received a private red signal compared to all the other treatments $\left(-1.575^{* * *}\right)$. American subjects were also less likely to send a red signal when they received a private red signal in the UI and EI treatment compared to EE $\left(-1.082^{* *}\right.$

\footnotetext{
${ }^{30} \mathrm{We}$ also ran these same models, but with the addition of the demographic characteristics of the subjects as covariates (in particular, age, gender and whether they study economics or business). These regressions are in the appendix and present results quite similar to those reported here. In the regression which uses the Italian data, we however lose 1200 observations (25 signals for 48 subjects) since we did not collect the demographic characteristics in the first sessions run in Italy. We also compare the proportion of Custodians with a background in economics and business between US and Italy (see appendix). Previous studies have in fact observed that students in economics are significantly more corrupted (Frank and Schulze, 2000) and tend to steal more money (Zizzo, 2004) than others. The proportion of Custodians with a background in economics or business is very small in both locations and the difference is not statically significant. Hence, it cannot explain the higher level of dishonesty of the Italian Custodians.
} 
and $-1.188^{* * *}$ ). Compared to American subjects in the EE treatment, there is also strong evidence that Americans in the UE treatment were overall more likely to send a red signal when the private signal was red $\left(1.417^{* *}\right)$, and less likely to send a red signal when the signal was green $\left(-1.287^{*}\right)$. Italian subjects in the UI treatment were less likely to send a red signal when they received a private red signal compared to all the other treatments $\left(-1.575^{* * *}\right)$. These results confirm the fact that, while for American subjects increased dishonesty was associated with a decrease in perceived just deserts quite independently of the equality of the incomes, Italian subjects tended to behave more dishonestly only when the income distribution was both inequitable and unequal.

\section{Discussion and Conclusion}

In this study we have focused attention on the role that just deserts - or its absenceplays in the maintenance of the basic societal norm of honesty. The motivation for this study is captured in the first epigraphic quote "If people feel that they are taken advantage of, why should they not rip off the system in return?" (Elster, 1989, p. 180). Specifically, we rely on equity theory (Adams, 1965) to construct and test the hypothesis that the violation of the just deserts principle induces greater dishonest on the part of those disadvantaged by the violation. Despite (or perhaps because of) its simplicity, equity theory offers a general framework for investigations of the violations of just deserts and their subsequent effect on dishonesty.

While the proposition that those who feel as they have been treated unfairly are more likely to behave dishonestly may be intuitively appealing, aside from Houser et al. (2012), this proposition has received scant attention. We use an empirical strategy which draws both on a novel experimental design - in which we manipulate both the equality and the equity of the income allocation procedure - and multilevel regression analysis of cross-national World Values Survey data, to uncover convergent evidence that supports this claim. Moreover, we uncover differences between the behavior between the Italian and American experimental subject pools, suggesting - in line with previous research - that Americans are more sensitive to meritocratic concerns than are Italians. Kunovich and Slomczynski (2007) provides evidence that the levels of both actual and perceived meritocracy are lower in Italy than the United States. Therefore, we can conjecture that because Italians are "pre-treated" with lower expectations of just deserts, they can more easily justify selfish dishonesty than Americans. On the other hand, precisely because Americans tend to have higher expectations for meritocracy, they may be more sensitive to its absence. Another potential explanation could be that Italians have a shared understanding of low expectations in terms of effort put into 
work (Gambetta et al., 2009). As a result, they may feel that meritocracy is not particularly relevant if the expectation is that compatriots will most likely shirk (though the causality most likely runs in both directions).

As discussed above, situations in which self-fulfilling beliefs sustain multiple equilibria occur in the relationship between just deserts and attitudes toward redistribution (Bénabou and Tirole, 2006; Alesina et al., 2001; Alesina and Glaeser, 2004; Alesina and Giuliano, 2009). We speculate that violations of the principle of just deserts can similarly generate multiple equilibria with respect to dishonesty. If individuals respond to an absence of just deserts with dishonesty and corruption, then this might result in a societal distribution of resources which is lacking to an even greater degree in just deserts, thus creating a self-reinforcing spiral into an ever-more dishonest and less virtuous society.

From a methodological point of view, in our empirical approach we exploit two sources of evidence, combining a Multi-Level Model based on WVS and a cross-country laboratory experiment. The multilevel modeling allows us to control for and isolate the country level effects and therefore get a cleaner measure of our theoretical relationship of interest, which is then tested in the experimental analysis. The results provide convergent evidence of this relationship, making a more convincing case than either evidence on its own. 


\section{A Appendix: Additional Demographic Information and Analysis}

\section{A.1 Demographic Variables}

Table A.1 reports the demographic variables collected at the end of the experiment. We did not collect the demographic information in the first sessions run in Italy (56 out of 144 subjects).

Table A.1: Demographic Variables

\begin{tabular}{l|c|c}
\hline Characteristics & US & Italy \\
\hline \hline Gender & $(\mathrm{n}=161)^{\mathrm{a}}$ & $(\mathrm{n}=96)$ \\
Female & $52.17 \%(84)$ & $58.33 \%(56)$ \\
Male & $47.83 \%(77)$ & $41.67 \%(40)$ \\
\hline Age & $(\mathrm{n}=162)^{\mathrm{b}}$ & $(\mathrm{n}=96)$ \\
Mean & 20.15 & 22.82 \\
St. dev. & 2.70 & 3.23 \\
\hline Econ./Bus. & $(\mathrm{n}=162)^{\mathrm{b}}$ & $(\mathrm{n}=88)^{\mathrm{c}}$ \\
No & $91.98 \%(149)$ & $85.23 \%(75)$ \\
Yes & $8.02 \%(13)$ & $14.77 \%(13)$ \\
\hline Citizenship & $(\mathrm{n}=129)^{\mathrm{d}}$ & $(\mathrm{n}=144)$ \\
non-American/non-Italian & $13.95 \%(18)$ & $0 \%(0)$ \\
non-American/Italian & $86.05 \%(111)$ & $100 \%(144)$ \\
\hline Years in US & $(\mathrm{n}=18)$ & \\
Mean & 4.32 & \\
St. Dev. & 5.06 & \\
\hline
\end{tabular}

Notes: a Three subjects did not report their gender. ${ }^{\mathrm{b}}$ Two subjects did not report the age and their field of studies. ${ }^{\mathrm{c}}$ Eight subjects did not report their field of studies. ${ }^{\mathrm{d}}$ We did not include this question in the first sessions run in US, and, therefore we do not have the information for 32 subjects. In addition, three subjects failed to report this information, resulting in a total of 35 missing observations.

\section{A.2 Comparison of Custodians with a Background in Economics or Business}

There have been a number of studies (e.g. Zizzo, 2004; Frank and Schulze, 2000) which have found that students studying economics behave in a more self interested fashion in experiments. It is possible, then, that Italian subjects behaved more dishonestly simply because there were a higher proportion of participants who studied economics. To test this possibility we can compare the proportion of Custodians with a major in economics in Italy and US (see Table A.2). ${ }^{31}$ The proportion of Custodians with a major in economics is not

\footnotetext{
${ }^{31}$ We do not have the information about the field of studies for all the participants. In particular, 2 out of 164 subjects in the US sessions did not report their field of studies. In addition, we did not collect the demographic information in the first sessions run in Italy (56 out of 144 subjects). This does not pose any
} 
very large in either of the locations and the difference is not statistically significant (Chisquared test, $p=0.203$ ). If we also include those Custodians with a major in business (see Table A.3), the difference is still not statically significant (Chi-squared test, $p=0.664$ ).

\begin{tabular}{|c|c|c|c|}
\hline Economics & US & Italy & Tot \\
\hline No & $95.12 \%(78)$ & $89.13 \%(41)$ & 92.97\% (119) \\
\hline Yes & $4.88 \%(4)$ & $10.87 \%(5)$ & $7.03 \%(9)$ \\
\hline Tot. & $100 \%(82)$ & $100 \%(46)$ & $100 \%(128)$ \\
\hline
\end{tabular}

Table A.3: Field of Studies for Custodians: Economics \& Business vs. Others

\begin{tabular}{|l|c|c|c|}
\hline Economics or Business & US & Italy & Tot \\
No & $91.46 \%(75)$ & $89.13 \%(41)$ & $90.63 \%(116)$ \\
Yes & $8.54 \%(7)$ & $10.87 \%(5)$ & $9.38 \%(12)$ \\
Tot. & $100 \%(82)$ & $100 \%(46)$ & $100 \%(128)$
\end{tabular}

\section{A.3 Regression analysis with Demographic Variables}

Table A.4 displays the results from a specification similar to the regression analysis presented in the Section 5 of the paper. For the Italian subjects, we do not have observations on the demographics for the UI and UE treatments. So when we control for the demographics, those data are dropped. The main results are unchanged. Consistently with previous studies who show that students in economics display a more rational and profit-maximizing behavior (e.g. Zizzo, 2004; Frank and Schulze, 2000), students with a background in economics are more likely to report a green signal, both in Italy and US.

limitation to our analysis since the subjects were, in both locations, recruited randomly using the subject pools maintained through ORSEE (Greiner, 2004). Hence, the sub-sample of Italian subjects for which we have the information about the field of study should be representative of all the Italian subjects that participate in our experiment. 
Table A.4: Regression with Demographic Variables

\begin{tabular}{lcccccc}
\hline & \multicolumn{3}{c}{ US } & \multicolumn{3}{c}{ Italy } \\
\hline \hline & $\mathrm{b}$ & $\mathrm{se}$ & $\mathrm{p}$ & $\mathrm{b}$ & $\mathrm{se}$ & $\mathrm{p}$ \\
\hline Red signal(t) & $4.305^{* * *}$ & 0.324 & 0.000 & $5.177^{* * *}$ & 0.42 & 0.000 \\
Red Signal (t-1) & $-0.413^{* *}$ & 0.173 & 0.017 & -0.217 & 0.254 & 0.392 \\
Red Signal (t-1)+(t-2) & 0.139 & 0.201 & 0.489 & -0.034 & 0.306 & 0.912 \\
Red Signal $\times \mathrm{UI}$ & $-1.067^{* *}$ & 0.448 & 0.017 & & & \\
Red Signal $\times$ UE & $1.431^{* *}$ & 0.638 & 0.025 & & & \\
Red Signal $\times \mathrm{EI}$ & $-1.168^{* * *}$ & 0.416 & 0.005 & $-0.913^{*}$ & 0.534 & 0.087 \\
UI & -0.62 & 0.684 & 0.365 & & & \\
UE & $-1.17^{*}$ & 0.678 & 0.084 & & & \\
EI & -0.489 & 0.603 & 0.418 & 0.282 & 0.657 & 0.668 \\
Effort & -0.115 & 0.259 & 0.656 & -0.336 & 0.492 & 0.495 \\
Age & -0.039 & 0.124 & 0.75 & 0.092 & 0.07 & 0.189 \\
Gender & 0.028 & 0.434 & 0.949 & -0.718 & 0.607 & 0.237 \\
Economics & $-1.447^{*}$ & 0.801 & 0.071 & $-1.679^{*}$ & 0.92 & 0.068 \\
Period & -0.009 & 0.01 & 0.395 & 0 & 0.015 & 0.997 \\
Constant & -0.308 & 2.662 & 0.908 & -4.077 & 2.43 & 0.093 \\
\hline Obs & 1886 & & & 1058 & & \\
Pseudo Chi2 & 0.677 & & & 0.427 & & \\
Df & 14 & & & 10 & & \\
Prob $>$ F & 0 & & & 0 & &
\end{tabular}




\section{B Appendix: Additional MLM Analysis}

As discussed in Section 4 of the paper, the results regarding tolerance for dishonesty and corruption as a function of belief in just deserts is robust to our choice of dependent variable. In Section 4, we report the results from an MLM regression using the WVS item which asks whether it is justifiable to "cheat on your taxes if you have a chance." Here, instead, we use an average of this item along with three other items: "accepting a bribe in the course of ones duties"; "claiming undeserved government benefits" and "avoiding a fare on public transport." ${ }^{32}$ The estimating equations remain the same as those reported in Section 4 with the only difference being the item(s) used for the dependent variable. Table B.1 reports the results of this model. Though the coefficients for some of the control variables change sign, the coefficient for the just deserts ("hardwork") variable remains virtually unchanged. The same pattern emerges if we take any of these items separately as the dependent variable.

Table B.1: Justifying Dishonest/Corrupt Acts: Random Intercepts Model

\begin{tabular}{lccc}
\hline \hline Variable & Coefficient & S.E. & P-value \\
\hline Hardwork & 0.062 & 0.002 & 0.000 \\
Equality & -0.004 & 0.002 & 0.006 \\
Trust & 0.013 & 0.011 & 0.218 \\
Income & 0.019 & 0.002 & 0.000 \\
Gini & 0.009 & 0.002 & 0.000 \\
Corruption & -0.086 & 0.002 & 0.000 \\
GDP & 0.001 & 0.0002 & 0.000 \\
$\gamma_{00}$ & 1.945 & 0.114 & 0.00 \\
$\tau_{00}$ & 0.583 & 0.051 & \\
$\sigma^{2}$ & 1.594 & 0.003 & \\
$N$ (\# obs) & 120,733 & & \\
$M$ (\# groups) & 68 & & \\
Log-Likelihood & -227753 & & \\
LR test $\left(\chi_{2,1}^{2}\right)$ & 11746.6 & & 0.000 \\
\hline
\end{tabular}

\footnotetext{
${ }^{32}$ There are additional items which are conceptually related, including whether it is justifiable to engage in the following activities: "joyriding", "lying", "paying cash to avoid taxes", "buying stolen goods", "keeping money you have found" and "failing to report damage you've done accidentally to a parked vehicle." However, because the there is much less coverage for these items, we do not report any results for them here. Nonetheless, the relationship between a belief in just deserts and these items is the same as for the others we report here.
} 


\section{Appendix: Instructions}

The same instructions, translated in Italian, were used for the sessions conducted in Italy. The Italian version of the instructions is available upon request.

\section{Introduction}

Welcome to the Decision Experiments Laboratory here at Stony Brook University. Today, you will participate in a study of individual behavior lasting about an hour for which there is a cash payment that depends on your choices and the choices of other participants.

During the experiment your earnings will be calculated in wolfies. Each wolfie is worth 1 cent. Payment will be made in cash at the end of this session and the payments will be carried out in such a way that no other participant will know how much you earned.

The experiment is divided into three phases. At each stage you will be asked to make certain decisions or to answer some questions.

From this point on, all talking or other communication with other participants is prohibited. If you want to ask a question, raise your hand. Please turn off you cell phones and other devices and store them for the duration of the experiment.

\section{Phase 1}

In this stage you will be shown a text in a foreign language and you have to record on each line the number of times the letters "c" and "e" appear. You have 5 minutes to complete this exercise.

After all participants have completed the letter counting task, the computer will produce a ranking of all participants based on their performance on the task. Your performance is measured by taking the deviation, in absolute value, between the true number of c's and e's in each line of the text and the number you recorded. This tally is recorded for each line and then summed over all 15 lines of text. The participant with the lowest score is then considered to have the best performance. The 12 participants with the lowest scores will be classified as "high-performers" while the 12 participants with the highest scores will be classified as "low-performers".

\section{For Treatments, UE, UI and EE}

After your performance has been ranked, the computer will randomly select your partner for Phase 2. If you are a "high-performer" you will be paired with a "low-performer" and if you are a "low-performer" then you will be paired with a "high-performer".

\section{$-\mathrm{OR}-$}

\section{For Treatment EE}

After your performance has been ranked, the computer will randomly select your partner 
for Phase 2. If you are a "high-performer" you will be paired with another "high-performer" and if you are a "low-performer" then you will be paired with another "low-performer".

The assignment of your initial payment is based on whether you are classified as a high performer or a low-performer. There are four possible cases for the payment:

In three of the four scenarios the payment to the high performers will be greater than or equal to the payment to the low performers.

In one out of the four scenarios the payment to the high performers will be less than the payment to the low performers.

You will be notified of which scenario you have been assigned to at the end of phase 1, and just before the start of phase 2 .

From here on out, please carefully follow the instructions on the screen. Remember to click "continue" so the group can continue with the experiment.

\section{Task}

Here is a text in a foreign language. For each row, count how many times the letters "c" and "e" appear. Then enter the number of times "c" appears in the first column, and enter the number of times "e" appears in the second column.

\section{Effort Report}

Before proceeding, indicate on a scale from 0 to 4 how much effort you dedicated to the preceding task $(0=$ minimal effort and $4=$ maximum effort $)$ :

\section{Classification}

The computer will now order the scores obtained by each participant on the effort task. The 12 participants with the highest scores will be henceforth called "high performers", while the 12 participants with the lowest scores will be referred to as "low performers".

\section{Treatment UE}

This session has been assigned to scenario 1. In scenario 1, high performers (B's) receive 1000 wolfies and low-performers (A's) receive 300 wolfies. As compensation for the effort task in phase 1 , the computer will credit you with:

- 1000 wolfies for the high performers

- 300 wolfies for the low performers

\section{$-\mathrm{OR}-$}

\section{Treatment UI}

This session has been assigned to scenario 1. In scenario 1, high performers (B's) receive 300 wolfies and low-performers (A's) receive 1000 wolfies. 
As compensation for the effort task in phase 1, the computer will credit you with:

- 300 wolfies for the high performers

- 1000 wolfies for the low performers

- OR-

\section{Treatment EI and EE}

This session has been assigned to scenario 1 . In scenario 1, high performers (B's) receive $1000[$ high] $/ 300$ [low] wolfies and low-performers (A's) receive 1000[high]/300[low] wolfies.

As compensation for the effort task in phase 1, the computer will credit you with:

- $1000[$ high $] / 300[$ low] wolfies for the high performers

- $1000[$ high] $/ 300[$ low] wolfies for the low performers

This amount will be paid to each participant together with the earnings from Phase 2 and 3. Your score in the Phase 1 is among the 12 highest scores. For this reason you are classified as a high-performer. The computer will assign you 1000/300 wolfies.

\section{- OR-}

Your score in the Phase 1 is among the 12 lowest scores. For this reason you are classified as a low-performer. The computer will assign you 300/1000 wolfies.

\section{Phase 2}

\section{For Treatments UE, UI and EE}

For this phase, you have now been paired with a partner. Each low-performer which we will refer to as "A" has been randomly paired with a high-performer, which we will refer to as "B". B has been put in charge of an account of 1500 wolfies which belongs to A. B will receive 25 binary signals (RED / GREEN). Each signal is randomly generated by the computer and each signal red or green has an equal probability of occurring each of the 25 times (thus, it is like flipping a coin). The random value of each signal is communicated privately to only B. The green signal means that B is entitled to take 40 wolfies from the A's account. The red signal means that B leaves A's account untouched.

\section{- OR-}

\section{For Treatments EE}

For this phase, you have now been paired with a partner. Each low[high]-performer which we will refer to as "A" has been randomly paired with a low[high]-performer, which we will refer to as "B". B has been put in charge of an account of 1500 wolfies which belongs to A. B will receive 25 binary signals (RED / GREEN). Each signal is randomly generated by the 
computer and each signal red or green has an equal probability of occurring each of the 25 times (thus, it is like flipping a coin). The random value of each signal is communicated privately to only B. The green signal means that B is entitled to take 40 wolfies from the A's account. The red signal means that B leaves A's account untouched.

The total number of red and green signals reported by B will be announced to $\mathrm{A}$ at the end of phase 2, together with the net amount of his or her account.

What ultimately matters for the actual transfer of payments from the account as well as what is communicated to each A, are the signals as reported the B partner of each A: in other words, if $B$ registers a signal different from that generated by the computer, whether money is transferred from A's account to B's account is determined by the reported signal, not the computer-generated signal. Once B has recorded a signal, its value can no longer be changed.

At the end of this phase, each A subject will receive the amount of the original account (1000 wolfies) less the number of green signals reported by their partner times 60 (because 60 wolfies is lost with the reporting of each green signal). A's must wait for their partners

to receive and report all 25 signals. During this time each A will be asked to predict the number of green signals that they expect their partner to report.

\section{Test Rounds}

Before we begin Phase 2 each of you will assume the role of B for 4 practice rounds.

These practice rounds are for illustrative purposes only and thus do not affect final earnings.

In each round will receive a signal, red or green, and then you will be asked to report the signal. The computer will then display the hypothetical effects of the reported signal on the earnings of each partner.

\section{Explanation}

In this round of testing you have received a red signal. We have asked you to record the signal incorrectly as green. As a result, if you were B you would have transferred 40 wolfies from A's account into your account. This is because the transfer is determined by the reported signal rather than the signal that was generated by the computer.

\section{Assignment to Scenarios}

This session has been assigned to scenario 3. In scenario 1, high performers (B's) receive 1000 (300) wolfies and low-performers (A's) receive 1000 (300) wolfies.

This session has been assigned to scenario 4. In scenario 2, high performers (B's) receive 1000 (300) wolfies and low-performers (A's) receive 1000 (300) wolfies. 


\section{Assigning the role of low-performer or high-performer}

The computer has now assigned your roles and partners for this session Your performance ranking classifies you as a low-performer and therefore you will play the role of A. For this reason, you are the owner of the account with 1000 wolfies. You have been randomly matched to a participant whose performance classifies him or her as a high-performer, and thus will play the role of B. Your partner will administer your 1000-wolfie account based on the values reported after observing the series of randomly generated signals. During this stage, your only task is to predict the number of green signals you expect to be recorded by your partner. (Remember that each of the two signals is equally likely to occur each time, therefore the process is similar to flipping a coin 25 times.) Recall that because of the scenario you were selected to be in and your status as a low-performer you will receive 200 (700) wolfies in addition to the amount determined by the reporting of the signals in this phase.

\section{$-\mathrm{OR}-$}

The computer has now assigned your roles and partners for this session. Your performance ranking classifies you as a high-performer and therefore you will play the role of B. You have been randomly matched with a low-performer, who will be designated as player A. You will administer the 1000-wolfie account owned by A. You will receive a series of 25 binary signals, your recording of which will determine whether a transfer from your partner's account to your account takes place. Recall that because of the scenario you were selected to be in and your status as a high-performer you will receive 700 (200) wolfies in addition to the amount determined by the reporting of the signals in this phase.

\section{Phase 3}

Phase 2 is completed. Before showing you the results, we ask you to complete a task identical to the one you completed in Phase 1 . You will be shown a new text in a foreign language and you have to record on each line the number of times the letters "c" and "e" appear. Again, you have 5 minutes to do this exercise. Once the time expires, you will receive a payment on the basis of correct answers. For each correct count, you will receive 10 wolfies.

\section{Effort Report}

Before proceeding, once again indicate on a scale from 0 to 4 how much effort you dedicated to the preceding task ( $0=$ minimal effort and $4=$ maximum effort). 


\section{References}

Adams, J. S. (1963). Towards an understanding of inequity. The Journal of Abnormal and Social Psychology, 67(5):422.

Adams, J. S. (1965). Inequity in social exchange. Advances in experimental social psychology, 2(267-299).

Alesina, A. and Angeletos, G. (2005a). Corruption, inequality, and fairness. Journal of Monetary Economics, 52(7):1227-1244.

Alesina, A. and Angeletos, G.-m. (2005b). Fairness and Redistribution. American Economic Review, 95(4):960-980.

Alesina, A. and Glaeser, E. (2004). Fighting poverty in the US and Europe: A world of difference. Oxford University Press Oxford.

Alesina, A., Glaeser, E., and Sacerdote, B. (2001). Why doesn't the us have a european-style welfare system? Technical report, National Bureau of Economic Research.

Alesina, A. and La Ferrara, E. (2005). Preferences for redistribution in the land of opportunities. Journal of Public Economics, 89(5-6):897-931.

Alesina, A. F. and Giuliano, P. (2009). Preferences for redistribution. Technical report, National Bureau of Economic Research.

Alessio, J. C. (1980). Another folly for equity theory. Social Psychology Quarterly, pages $336-340$.

Almås, I., Cappelen, A. W., Sørensen, E. Ø., and Tungodden, B. (2010). Fairness and the development of inequality acceptance. Science, 328(5982):1176-1178.

Ayal, S. and Gino, F. (2011). Honest rationales for dishonest behavior. The Social Psychology of Morality: Exploring the Causes of Good and Evil. Washington, DC: American Psychological Association.

Balafoutas, L., Kocher, M. G., Putterman, L., and Sutter, M. (2013). Equality, equity and incentives: An experiment. European Economic Review.

Bénabou, R. and Tirole, J. (2006). Belief in a just world and redistributive politics. The Quarterly journal of economics, 121(2):699-746.

Bloom, M. (1999). The performance effects of pay dispersion on individuals and organizations. Academy of Management Journal, 42(1):25-40.

Bolton, G. E., Brandts, J., and Ockenfels, A. (2005). Fair procedures: Evidence from games involving lotteries. The Economic Journal, 115(506):1054-1076.

Bucciol, A. and Piovesan, M. (2011). Luck or cheating? a field experiment on honesty with children. Journal of Economic Psychology, 32(1):73-78. 
Burrows, P. and Loomes, G. (1994). The Impact of Fairness on Bargaining Behaviour. Empirical Economics, pages 201-221.

Cappelen, A., Hole, A., Sorensen, E., and Tungodden, B. (2007). The pluralism of fairness ideals: An experimental approach. American Economic Review, 97(3).

Cappelen, A. W., Sørensen, E. Ø., and Tungodden, B. (2010). Responsibility for what? fairness and individual responsibility. European Economic Review, 54(3):429-441.

Dal Bó, P., Foster, A., and Putterman, L. (2010). Institutions and behavior: Experimental evidence on the effects of democracy. The American Economic Review, 100(5):2205-29.

d'Anjou, L., Steijn, A., and Van Aarsen, D. (1995). Social position, ideology, and distributive justice. Social Justice Research, 8(4):351-384.

Durante, R., Putterman, L., and van der Weele, J. (2013). Preferences for redistribution and perception of fairness: An experimental study. Journal of the European Economic Association.

Elster, J. (1989). Solomonic judgements: Studies in the limitation of rationality. Cambridge University Press.

Erat, S. and Gneezy, U. (2012). White lies. Management Science, 58(4):723-733.

Esarey, J., Salmon, T., and Barrilleaux, C. (2012). Social insurance and income redistribution in a laboratory experiment. Political Research Quarterly, 65(3):685-698.

Fischbacher, U. (2007). z-tree: Zurich toolbox for ready-made economic experiments. Experimental economics, 10(2):171-178.

Fischbacher, U. and Föllmi-Heusi, F. (2013). Lies in disguise - an experimental study on cheating. Journal of the European Economic Association, 11(3):525-547.

Fong, C. (2001). Social preferences, self-interest, and the demand for redistribution. Journal of Public Economics, 82(2):225-246.

Frank, B. and Schulze, G. G. (2000). Does economics make citizens corrupt? Journal of Economic Behavior \& Organization, 43(1):101 - 113.

Frey, B. S., Benz, M., and Stutzer, A. (2004). Introducing procedural utility: Not only what, but also how matters. Journal of Institutional and Theoretical Economics JITE, 160(3):377-401.

Frohlich, N. and Oppenheimer, J. A. (1990). Choosing justice in experimental democracies with production. The American Political Science Review, pages 461-477.

Frohlich, N. and Oppenheimer, J. A. (1992). Choosing justice: An experimental approach to ethical theory, volume 22. University of California Press. 
Gambetta, D., Origgi, G., et al. (2009). L-worlds. The curious preference for low quality and its norms. Oxford Series of Working Papers in Linguistics, pages 1-23.

Gelman, A. and Hill, J. (2007). Data analysis using regression and hierarchical/multilevel models. Cambridge University Press: Cambridge, UK.

Gijsberts, M. (2002). The legitimation of income inequality in state-socialist and market societies. Acta Sociologica, 45(4):269-285.

Gilliland, S. W. (1993). The perceived fairness of selection systems: An organizational justice perspective. Academy of management review, 18(4):694-734.

Gino, F. and Pierce, L. (2009). Dishonesty in the name of equity. Psychological Science, 20(9):1153-1160.

Gino, F. and Pierce, L. (2010). Lying to level the playing field: Why people may dishonestly help or hurt others to create equity. Journal of Business Ethics, 95(1):89-103.

Greenberg, J. (1987). A taxonomy of organizational justice theories. Academy of Management review, 12(1):9-22.

Greenberg, J. (1990). Employee theft as a reaction to underpayment inequity: The hidden cost of pay cuts. Journal of applied psychology, 75(5):561.

Greiner, B. (2004). The online recruitment system orsee 2.0-a guide for the organization of experiments in economics. University of Cologne, Working paper series in economics, 10(23):63-104.

Großer, J. and Reuben, E. (2013). Redistribution and market efficiency: An experimental study. Journal of Public Economics.

Guiso, L., Sapienza, P., and Zingales, L. (2008). Alfred marshall lecture: social capital as good culture. Journal of the European Economic Association, 6(2-3):295-320.

Harris, R. J. (1976). Handling negative inputs: On the plausible equity formulae. Journal of Experimental Social Psychology, 12(2):194-209.

Hoffman, E., McCabe, K., Shachat, K., and Smith, V. (1994). Preferences, Property Rights, and Anonymity in Bargaining Games. Games and Economic Behavior, 7:346-380.

Houser, D., Vetter, S., and Winter, J. (2012). Fairness and cheating. European Economic Review.

Huseman, R. C., Hatfield, J. D., and Miles, E. W. (1987). A new perspective on equity theory: The equity sensitivity construct. Academy of Management Review, 12(2):222-234.

Inglehart, R. (1998). Human values and beliefs: A cross-cultural sourcebook: Political, religious, sexual, and economic norms in 43 societies: Findings from the 1990-1993 World Values Survey. University of Michigan Press. 
Jakiela, P. (2011). Social preferences and fairness norms as informal institutions: experimental evidence. American Economic Review, 101(3):509.

Kelley, J. and Evans, M. D. (1993). The legitimation of inequality: occupational earnings in nine nations. American Journal of Sociology, pages 75-125.

Konow, J. (1996). A positive theory of economic fairness. Journal of Economic Behavior \& Organization, 31(1):13-35.

Konow, J. (2000). Fair shares: Accountability and cognitive dissonance in allocation decisions. The American Economic Review, 90(4):1072-1091.

Krawczyk, M. (2010). A glimpse through the veil of ignorance: Equality of opportunity and support for redistribution. Journal of Public Economics, 94(1):131-141.

Kunovich, S. and Slomczynski, K. M. (2007). Systems of distribution and a sense of equity: A multilevel analysis of meritocratic attitudes in post-industrial societies. European sociological review, 23(5):649-663.

Leventhal, G. S. (1976). Fairness in Social Relationships. General Learning Press.

Lewin-Epstein, N., Kaplan, A., and Levanon, A. (2003). Distributive justice and attitudes toward the welfare state. Social Justice Research, 16(1):1-27.

López-Pérez, R. and Spiegelman, E. (2012). Why do people tell the truth? experimental evidence for pure lie aversion. Experimental Economics, pages 1-15.

Michelbach, P. A., Scott, J. T., Matland, R. E., and Bornstein, B. H. (2003). Doing Rawls justice: An experimental study of income distribution norms. American Journal of Political Science, 47(3):523-539.

Mitchell, G., Tetlock, P. E., Newman, D. G., and Lerner, J. S. (2003). Experiments behind the veil: Structural influences on judgments of social justice. Political Psychology, 24(3):519-547.

Moschetti, G. J. (1979). Calculating equity: Ordinal and ratio criteria. Social Psychology Quarterly, pages 172-176.

Ooghe, E., Schokkaert, E., et al. (2007). Equality of opportunity versus equality of opportunity sets. Social Choice and Welfare, 28(2):209-230.

Osberg, L. and Smeeding, T. (2006). "Fair" inequality? attitudes toward pay differentials: the United States in comparative perspective. American sociological review, 71(3):450-473.

Rabin, M. (1993). Incorporating fairness into game theory and economics. The American economic review, pages 1281-1302.

Robert, I. and Arnab, M. (2013). Is dishonesty contagious? Economic Inquiry, 51(1):722734. 
Rose-Ackerman, S. (2001a). Trust and honesty in post-socialist societies. Kyklos, 54(2$3): 415-443$.

Rose-Ackerman, S. (2001b). Trust, honesty, and corruption: reflection on the state-building process. European Journal of Sociology, 42:27-71.

Rothstein, B. and Uslaner, E. M. (2005). All for all: Equality, corruption, and social trust. World politics, 58(01):41-72.

Ruffle, B. (1998). More Is Better, But Fair Is Fair: Tipping in Dictator and Ultimatum Games. Games and Economic Behavior, 23(2):247-265.

Rutström, E. and Williams, M. B. (2000). Entitlements and fairness: an experimental study of distributive preferences. Journal of Economic Behavior $\mathscr{G}$ Organization, 43(1):75-89.

Schokkaert, E. and Devooght, K. (2003). Responsibility-sensitive fair compensation in different cultures. Social Choice and Welfare, 21(2):207-242.

Scott, J. T. and Bornstein, B. H. (2009). Whatiæ¡s fair in foul weather and fair? distributive justice across different allocation contexts and goods. Journal of Politics, 71(3):831-846.

Scott, J. T., Matland, R. E., Michelbach, P. A., and Bornstein, B. H. (2001). Just deserts: an experimental study of distributive justice norms. American Journal of Political Science, pages $749-767$.

Sen, A. (2000). Merit and justice. In Arrow, K., Bowles, S., and Durlauf, S., editors, Meritocracy and Economic Inequality, pages 5-16. Princeton University Press.

Shalvi, S., Eldar, O., and Bereby-Meyer, Y. (2012). Honesty requires time (and lack of justifications). Psychological science, 23(10):1264-1270.

Shalvi, S., Handgraaf, M. J., and De Dreu, C. K. (2011). Ethical manoeuvring: why people avoid both major and minor lies. British Journal of Management, 22(s1):S16-S27.

Suri, S., Goldstein, D. G., and Mason, W. A. (2011). Honesty in an online labor market. In Human Computation.

Svallfors, S. (1997). Worlds of welfare and attitudes to redistribution: A comparison of eight western nations. European Sociological Review, 13(3):283-304.

Uslaner, E. M. (2008). Corruption, inequality, and the rule of law. Cambridge University Press Cambridge.

Walster, E., Berscheid, E., and Walster, G. W. (1973). New directions in equity research. Journal of personality and social psychology, 25(2):151.

Zak, P. J. and Knack, S. (2001). Trust and growth. The economic journal, 111(470):295-321.

Zizzo, D. J. (2004). Inequality and procedural fairness in a money-burning and stealing experiment. In Cowell, F., editor, Inequality, Welfare and Income Distribution: Experimental Approaches, volume 11, pages 215 - 247. Elsevier. 


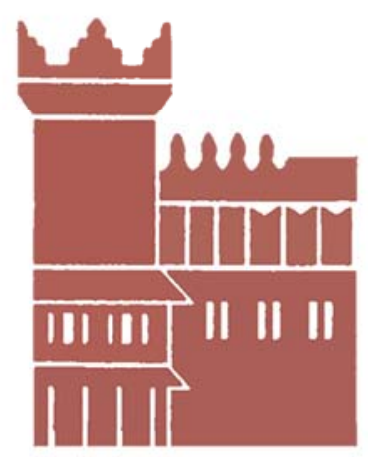

Alma Mater Studiorum - Università di Bologna DEPARTMENT OF ECONOMICS

Strada Maggiore 45

40125 Bologna - Italy

Tel. +39051 2092604

Fax +390512092664

http://www.dse.unibo.it 